\title{
Spatially Restricted Expression of Dlx-1, DIx-2 (Tes-1), Gbx-2, and Wnt-3 in the Embryonic Day 12.5 Mouse Forebrain Defines Potential Transverse and Longitudinal Segmental Boundaries
}

\author{
Alessandro Bulfone, ${ }^{1,2,4,5}$ Luis Puelles, ${ }^{6}$ Matthew H. Porteus, ${ }^{1,2,4,5}$ Michael A. Frohman, ${ }^{7}$ Gail R. Martin, ${ }^{3,5}$ and \\ John L. R. Rubenstein $1,2,4,5$ \\ 'Neurogenetics Laboratory, Departments of ${ }^{2}$ Psychiatry and ${ }^{3}$ Anatomy, and Programs in ${ }^{4}$ Neuroscience and \\ ${ }^{5}$ Developmental Biology, University of California, San Francisco, California 94143-0984, ${ }^{6}$ Department of Anatomy, Faculty \\ of Medicine, University of Murcia, Murcia, Spain 30100, and 'Department of Pharmacology, SUNY, Stonybrook, \\ New York 11794-8651
}

\begin{abstract}
The expression patterns of four genes that are potential regulators of development were examined in the CNS of the embryonic day 12.5 mouse embryo. Three of the genes, $D I x$ 1, DIx-2 (Tes-1), and Gbx-2, encode homeodomain-containing proteins, and one gene, $W n t-3$, encodes a putative secreted differentiation factor. These genes are expressed in spatially restricted transverse and longitudinal domains in the embryonic neural tube, and are also differentially expressed within the wall of the neural tube. $D / x-1$ and $D / x-2$ are expressed in two separate regions of the forebrain in an identical pattern. The $\mathbf{G b x - 2}$ gene is expressed in four domains, two of which share sharp boundaries with the domains of the D/x genes. One boundary is in the basal telencephalon between deep and superficial strata of the medial ganglionic eminence; the other boundary is in the diencephalon at the zona limitans intrathalamica. The $W n t-3$ gene is expressed in a dorsal longitudinal zone extending from the hindbrain into the diencephalon, where its expression terminates at the zona limitans intrathalamica. Reciprocal patterns of expression are found within the dorsal thalamus for the $G b x-2$ and $W n t-3$ genes. These findings are consistent with neuromeric theories of forebrain development, and based upon them we suggest a model for forebrain segmentatior
\end{abstract}

[Key words: forebrain, diencephalon, telencephalon, development, segmentation, homeobox, Wnt, DIx, Gbx]

The embryonic nervous tube is initially composed of an undifferentiated pseudostratified neuroepithelium along its entire length. Depending upon the position along the anterior-posterior (A-P), dorsal-ventral (D-V), and medial-lateral (M-L) axes,

\footnotetext{
Received Jan. 12, 1993; revised Jan. 30, 1993; accepted Feb. 8, 1993.

We thank Teresa McGuinness and Danwen Xu for providing the $D l x-1$ cDNA clones, Roel Nusse for generously providing us with the $W n t-3$ clone, Pat O'Farrell and Thomas Kornberg for helpful discussions, and Melanie Bedolli for technical advice. This work was supported by grants to J.L.R.R. from the Pfizer Scholars, John Merck Scholars, NARSAD Young Investigator and Basil O'Connor-March of Dimes programs, and the NIMH (ROI MH49428-01); the Italian Association for Cancer Research (AIRC) to A.B.; and the Merck Corporation to M.H.P., who is a member of the MST program at Stanford.

Correspondence should be addressed to John L. R. Rubenstein, Neurogenetics Laboratory, Department of Psychiatry and Programs in Neuroscience and Developmental Biology, 401 Parnassus Avenue, USCF, San Francisco, CA 941430984.

Copyright $(1993$ Society for Neuroscience $0270-6474 / 93 / 133155-18 \$ 05.00 / 0$
}

cells differentiate and give rise to different neural structures. For instance, along the A-P axis the neural tube subdivides to form the spinal cord, the myclencephalon, the metencephalon, the mesencephalon, the diencephalon, and the telencephalon. Within each of these regions, subsequent differentiation of different neuroepithelial domains results in neural structures of distinct histologies. For example, as viewed from a cross section of the embryonic telencephalon, the neocortex derives from the dorsolateral wall of the cerebral vcsicle, the basal ganglia from the ventral wall, and the hippocampus and chorioid plexus from the medial wall.

The forebrain has remained relatively difficult to study because of its complex anatomy and because of the paucity of information regarding the mechanisms of its development. However, several studies over the last century have attempted to describe the early stages of forebrain development in terms of a neuromeric theory (von Kupffer, 1906; Rendahl, 1924; von Haller, 1929; Bergquist, 1932; Bergquist and Kallen, 1954, 1955; Coggeshall, 1964; Kallen, 1965; Vaage, 1969; Keyser, 1972; Gribnau and Geijsberts, 1985; Altman and Bayer, 1986, 1988; Puelles et al., 1987, 1991, 1992). Neuromeric theory postulates the existence of genetic fate determinants that subdivide the neural tube wall into transverse and longitudinal domains that develop along distinct pathways. The initial formulations of the theory were based on studies that principally used morphological data to determine the intersegmental and intrasegmental relationships between regions of the diencephalon and the telencephalon. Confirmation of the theory will require molecular evidence from the discovery of the genetic determinants of regional fate.

Hints regarding the genetic mechanisms that control the specification of different regions of the vertebrate body plan have come from the study of invertebrates. In Drosophila melanogaster the longitudinal axis of the embryo is subdivided into a scrics of scgments by the sequential expression of the gap, pair rule, and segment polarity genes (Levine and Harding, 1989). The final identity of segments is defined by the expression of the homeotic genes (McGinnis and Krumlauf, 1992). Most of the identified products of these genes are transcriptional regulators containing the homeodomain motif (Gehring, 1987), although positional information is also mediated by secreted proteins, such as the product of the wingless ( $w g$ ) gene (Baker, 1987; Rijsewijk et al., 1987). For instance, specification of the identity 
of the anterior and posterior half of each segment requires the interaction of $w g$ with several other genes, including the engrailed (en) homeobox gene (DiNardo et al., 1988; Heemskerk et al., 1991).

Regional differentiation of the vertebrate nervous system appears to employ some of the same mechanisms that mediate Drosophila development. Homologs of many Drosophila developmental control genes have been identified in vertebrates. For instance, the Hox genes, homologs of genes within the $A n$ tennapedia-Bithorax complex (Acampora et al., 1989; Duboule and Dollé, 1989; Graham et al., 1989; Kappen et al., 1989), are expressed in overlapping, but nonidentical, domains along the A-P axis in vertebrate embryos (for a review of Hox gene structure and expression, see McGinnis and Krumlauf, 1992).

The Hox genes appear to have an important role in controlling the development of the hindbrain. Within the hindbrain, the anterior boundaries of expression of individual Hox genes are found at the boundaries between structures called rhombomeres (Hunt et al., 1991), which are thought to represent neuronal segments (neuromeres). The evidence that differentiation of the hindbrain is controlled by the Hox genes comes from studies of mutations that inactivate $H o x-1.5$ and $H o x-1.6$ (Chisaka and Capecchi, 1991; Lufkin et al., 1991; Chisaka et al., 1992). Disruption of these genes results in abnormal differentiation of a subset of the neural tube-derived cells from the anteriormost region where these genes are expressed. In sum, available information suggests that the Hox genes have a role in determining the regional identities of cells along the A-P axis. This is analogous to the role that Hom genes play in defining the segmental identities in Drosophila (McGinnis and Krumlauf, 1992).

The $W n t$ gene family, vertebrate homologs of the Drosophila wg gene (McMahon et al., 1992; Nusse and Varmus, 1992), also have a role in controlling the development of specific regions of the CNS. Mice with mutations in the $W n t-1$ gene lack a midbrain (McMahon et al., 1992). In Drosophila, expression of the $w g$ gene affects the expression of several homeobox genes, including en (DiNardo et al., 1988) and distal-less (Dll; Cohen, 1990). In the mouse midbrain, Wnt- 1 and the $E n$ homeobox genes are coexpressed in overlapping domains (McMahon et al., 1992). Although at present there is no evidence for a functional link between the Wnt and homeobox genes in vertebrates, their interactions in Drosophila, and the coincidence of Wnt-I and $E n$ gene expression in the midbrain suggest that these gene families may interact in the regulation of vertebrate brain development.

Despite these recent advances in the study of hindbrain and midbrain development, until very recently there had been no identified genes that are candidates for specifying the identity of forebrain structures. However, in the last year, four families of homeobox genes $[D l x-1, D l x-2($ Tes- 1$), D l x-3$, and $D l x-4$ (Porteus et al., 1991; Price et al., 1991; Robinson et al., 1991); $N k x-2.1, N k x-2.2, N k x-2.3$, and $N k x-2.4$ (Price et al., 1992); $E m x-1$ and $E m x-2$ (Simeone et al., 1992a); and Otx-1 and Otx-2 (Simeone et al., 1992b)] and four members of the Wnt family [Wnt-3, Wnt-3a, Wnt-5a, and $W n t-7 b$ (Roelink and Nusse, 1991; McMahon et al., 1992)] were found to have restricted patterns of expression in the embryonic mouse forebrain. In this article we report on the patterns of expression of $D l x-1, D l x-2$, $W n t-3$, and the $G b x-2$ homeobox gene (Frohman et al., in press; also named MMoxA, Murtha et al., 1991) in the embryonic day 12.5 (E12.5) mouse. Our results show that each of these genes is expressed in spatially restricted transverse and longitudinal domains within the forebrain. The patterns of expression are consistent with ncuromcric models of the forebrain, thus supporting the concept that, like the hindbrain, the embryonic forebrain is segmented.

\section{Materials and Methods}

Mouse embryos. Timed-pregnant BALB/C mice were obtained from Simonsen Laboratories, Gilroy, CA. The day on which a copulatory plug was found was considered E0.5. The mothers were killed by cervical dislocation; the embryos were isolated and immediately frozen in 2-methylbutane cooled to the temperature of dry ice. The embryos were stored at $-80^{\circ} \mathrm{C}$ until they were used for cryostat sectioning.

cDNA probes. Two clones of the $D l x-1$ gene (Price et al., 1991) were independently isolated. A 2.8 kilobase $(\mathrm{kb})$ clone was purified from an E15 mouse telencephalon cDNA library (Porteus et al., 1992) by screening the library with a probe containing the Drosophila E86 homeobox (gift of W. McGinnis, Yale University). The identity of this clone was confirmed by DNA sequencing (A. Bulfone, D. Xu, and J. L. R. Rubenstein, unpublished observations). This cDNA is in the vector named E61 (Rubenstein et al., 1990). The $2.8 \mathrm{~kb}$ clone was used to make a digoxigenin probe used to label the sagittal sections shown in Figure 1 A 243 base pair (bp) $D l x-1$ clone was also obtained using PCR from the E15 cDNA library (W. McGuinness and J. L. R. Rubenstein, unpublished observations). The primers were designed based upon the nucleotide sequence that Price et al. (1991) submitted to GenBank. This fragment, which corresponds to the $243 \mathrm{bp}$ immediately $3^{\prime}$ to the $D l x-1$ homeobox and overlaps with the $2.8 \mathrm{~kb}$ fragment, was subcloned into a derivative of $\mathrm{pBS} \mathrm{KS}{ }^{-}$named $\mathrm{pBS}^{\mathrm{K}} \mathrm{KD}^{-}$(Dan Denney, Stanford University). The 243 bp fragment has no significant homology to the $D l x-2$ gene, and was used to make a ${ }^{35} S$-labeled probe, which was hybridized to the transverse sections shown in Figure 2, as well as to sagittal and coronal sections (data not shown). This fragment was also used to make digoxigenin probes used to label coronal sections (data not shown). Identical results were obtained with both the 2.8 and 0.243 kb probes.

The isolation of the $D l x-2(T e s-1)$ clone was described by Porteus et al. $(1991,1992)$. For these experiments, a subclone containing $730 \mathrm{bp}$ from the $3^{\prime}$ untranslated region was used to generate probes; this is the same fragment employed by Porteus et al. (1991) and is in a vector named E4 (Rubenstein et al., 1990).

The isolation of the $G b x-1$ and $G b x-2$ clones are described by M. A. Frohman and G. R. Martin (unpublished observations). A $G b x-1$ riboprobe was transcribed from a $0.5 \mathrm{~kb}$ fragment derived from the 3 untranslated region of the $G b x-1$ cDNA clone. A $G b x-2$ riboprobe was transcribed from a $0.65 \mathrm{~kb}$ fragment derived from the 3' untranslated region of the $G b x-2$ cDNA clone.

The Wnt-3 clone used in these studies was a $1.2 \mathrm{~kb}$ Sal I/Eco RI fragment derived from a noncoding and nonconserved region of the Wnt-3 cDNA (cloned in pGEM3Zf; Roelink and Nusse, 1991), and was a gift from Roel Nusse (Stanford University).

${ }^{35} \mathrm{~S}$-labeled riboprobes were made according to the procedure of Zoeller et al. (1989). The amount of radioactivity incorporated into acid precipitable counts using $1 \mu \mathrm{g}$ of DNA template was as follows: $D l x-1$, $2 \times 10^{8} \mathrm{cpm} ; D l x-2,1 \times 10^{8} \mathrm{cpm} ; G b x-1,1.6 \times 10^{8} \mathrm{cpm} ; G b x-2,1.2$ $\times 10^{8} \mathrm{cpm} ; W n t-3,2 \times 10^{8} \mathrm{cpm}$. Digoxigenin-labeled $\mathrm{cRNA}$ probes were synthesized by labeling these templates with digoxigenin-rUTP (Boehringer Mannheim). The in vitro transcription reaction was carried out as follows: $1 \mu \mathrm{g}$ of Proteinase $\mathrm{K}$-treated, linearized plasmid was incubated with $10 \mathrm{U}$ of T3 or T7 RNA polymerase (Stratagene) in 40 $\mathrm{mm}$ Tris- $\mathrm{HCl}$ pH $8.0,8 \mathrm{~mm} \mathrm{MgCl}, 2 \mathrm{~mm}$ spermidine, $50 \mathrm{~mm} \mathrm{NaCl}$, $30 \mathrm{~mm}$ dithiothreitol, $2.5 \mathrm{~mm}$ each rATP, rCTP, and rGTP, $1.65 \mathrm{~mm}$ rUTP, $0.85 \mathrm{~mm}$ digoxigenin-rUTP, $50 \mathrm{U}$ of RNase Block (Stratagene) at $37^{\circ} \mathrm{C}$ for $60 \mathrm{~min}$. The incubation was then repeated, in the same conditions, adding another $10 \mathrm{U}$ of RNA polymerase. The reaction was completed by an incubation with $10 \mathrm{U}$ of RNase-free DNase (Stratagene) and $10 \mathrm{U}$ of RNase Block (Stratagene) at $37^{\circ} \mathrm{C}$ for $10 \mathrm{~min}$ and an ethanol precipitation in $20 \mathrm{~mm}$ EDTA pH 8.0, $400 \mathrm{~mm} \mathrm{LiCl}$, and $1 \mathrm{mg} / \mathrm{ml}$ yeast tRNA. The riboprobes were dissolved in $300 \mu$ l of DEPC-treated water and $10 \mathrm{U}$ of RNase Block (Stratagene) and were stored at $-80^{\circ} \mathrm{C}$.

In situ hybridizations. In situ hybridization and autoradiography with ${ }^{35} \mathrm{~S}$-labeled riboprobes were carried out as described by Porteus et al. (1992), whereas the procedure was slightly modified for the digoxigenin probes. Following the hybridization, the slides were rinsed in $0.2 \times$ saline-sodium citrate, and were then washed twice in buffer $1(100 \mathrm{~mm}$ 

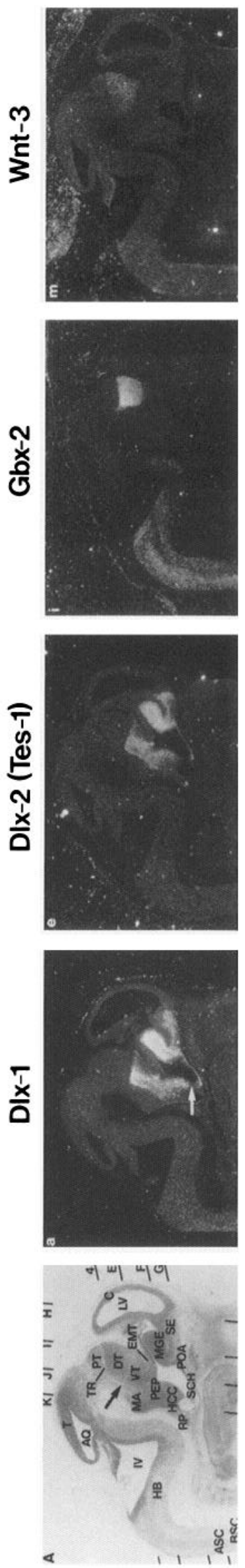
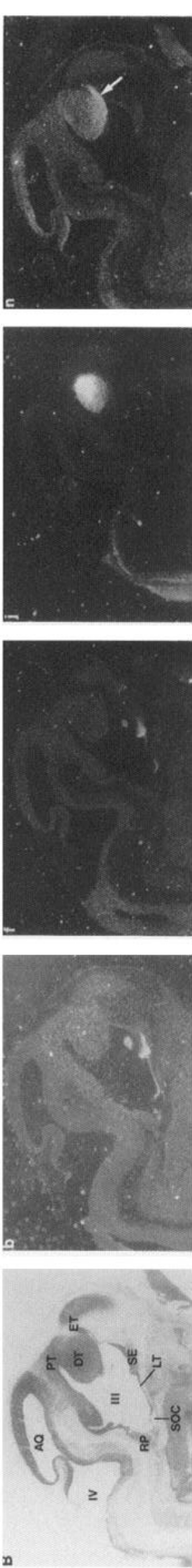
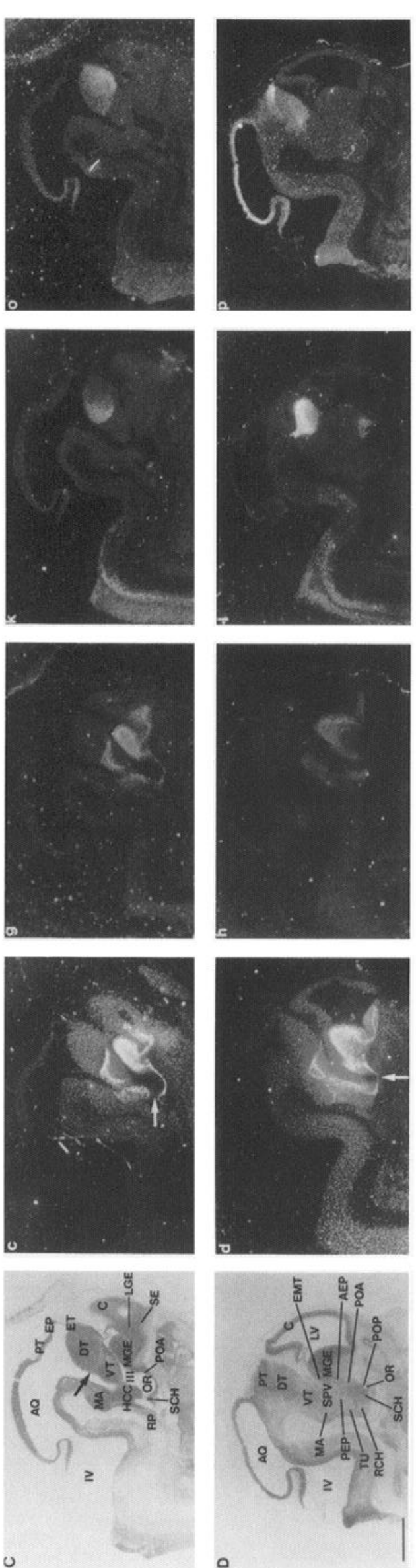

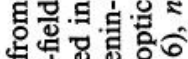

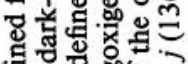
我 on $\circ \cdot{ }^{\circ}<\stackrel{5}{\circ}$

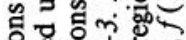

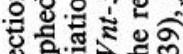
远.

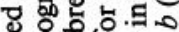
무유 क्ष 1 10 \% 둥 ป⿱一兀)

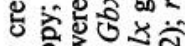

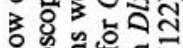
कㅇㅇㅇ. ․․ㄹㄷㄴ. Tे 㐘行

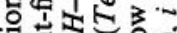
능 कू⿻ 凷

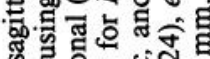

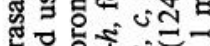
कृ ठ वि क 论 0 . กํํำ

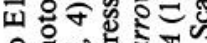
푼) क

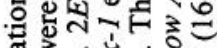
उ.

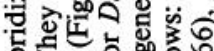

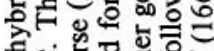
的它氞 《. 的 焉

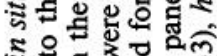
듕

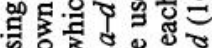

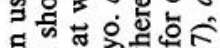
둥  记可

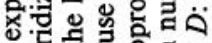

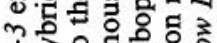

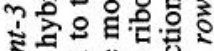
《㶽证 zZ응 的禺机

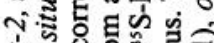
두원

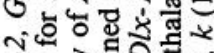

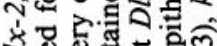

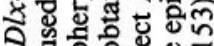
$\checkmark$ 员 我然这 จ영

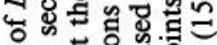

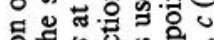

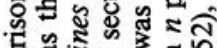

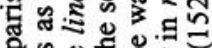

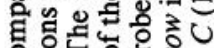

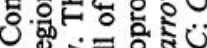

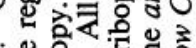

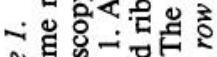
今。

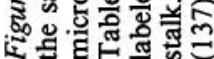



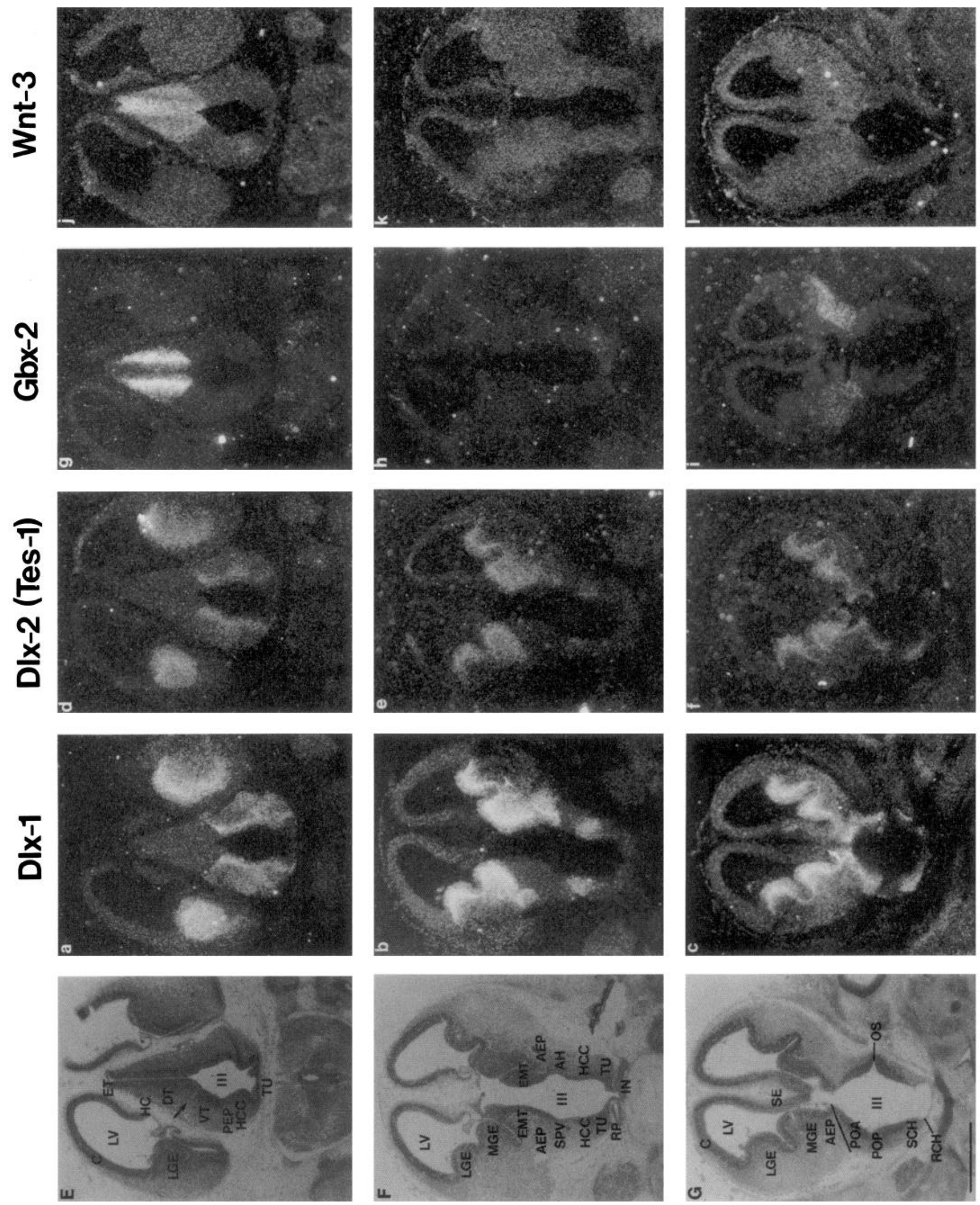
Tris- $\mathrm{HCl}, 150 \mathrm{~mm} \mathrm{NaCl}, \mathrm{pH} \mathrm{7.5)} \mathrm{for} 5 \mathrm{~min}$, incubated in the same buffer with $0.5 \%$ of Blocking Reagent (Boehringer Mannheim) for $1 \mathrm{hr}$, and incubated overnight at $4^{\circ} \mathrm{C}$ with alkaline phosphatase-conjugated anti-digoxigenin antiserum (Boehringer Mannheim), diluted 1:800 in buffer 1 containing $1 \%$ of Blocking Reagent. After two washes in buffer 1 for $10 \mathrm{~min}$ and two washes in buffer $2(100 \mathrm{~mm}$ Tris- $\mathrm{HCl}, 100 \mathrm{~mm}$ $\mathrm{NaCl}, 50 \mathrm{~mm} \mathrm{MgCl}_{2}, \mathrm{pH} 9.5$ ) for $10 \mathrm{~min}$, the slides were incubated overnight, in the dark, in buffer 2 containing levamisole $(2.4 \mathrm{mg} / 10 \mathrm{ml}$; Sigma), $45 \mu \mathrm{l}$ of NTB solution $(75 \mathrm{mg} / \mathrm{ml}$ of nitroblue tetrazolium salt in $70 \%$ dimethylformamide; Boehringer Mannheim), and $35 \mu \mathrm{l}$ of BCIP solution $(50 \mathrm{mg} / \mathrm{ml}$ of 5-bromo-4-chloro-3-indolyl phosphate toluidinium salt in dimethylformamide; Boehringer Mannheim). The slides were then rinsed in buffer $3(10 \mathrm{~mm}$ Tris-HCl, $1 \mathrm{~mm}$ EDTA, $\mathrm{pH} \mathrm{8.0)}$, in water, and quickly dehydrated and mounted. The results were analyzed using bright-field, dark-field, and epifluorescence microscopy using Olympus SZ40 dissecting and Zeiss Axiophot photomicroscopes.

\section{Results}

Previous studies of $D l x-1$ (Price et al., 1991, 1992) and $D l x-2$ (Tes-1) (Porteus et al., 1991; Robinson et al., 1991) suggested that these genes had overlapping patterns of expression in the forebrain, whereas $W n t-3$ had a complementary pattern to the Dl $x$ genes in the diencephalon (Roelink and Nusse, 1991). Furthermore, preliminary results showed that the $G b x$ genes also had restricted patterns of expression in the brain (Frohman and Martin, unpublished observations). To compare directly the patterns of expression of the $D l x-1, D l x-2$ (Tes-1), $G b x-1, G b x-2$, and $W n t-3$ genes in the E12.5 mouse embryos, in situ RNA hybridization experiments were carried out using serial sagittal, transverse, and coronal sections. The approximate positions of the transverse and coronal sections are shown in Figure $1 A$. The primary data are shown in Figures 1-5. Analysis of the spatial relationships of structures in the brain is complicated because of flexures and evaginations. We have attempted to simplify the interpretation of the results by presenting two schematic representations of the anatomy and of the patterns of gene expression (Figs. 6, 7). In each figure, longitudinal zones (such as the alar and basal plates) and transverse zones (theoretical neuromeres) are illustrated, and the expression patterns are shaded into the relevant regions. Figure 6 is a schematic medial view reconstruction of an E12.5 brain, whereas Figure 7 is a hypothetical topological map, in which the longitudinal and transverse axes are presented in orthogonal form. The expression patterns of the genes are fitted into the transverse and longitudinal domains according to the results described in the following sections. A description of the longitudinal and transverse zones of the forebrain is found in Puelles et al. (1987) and in the last scction of Discussion. To simplify the description of the transverse domains, we have designated six hypothetical prosencephalic neuromeres, $\mathrm{p} 1-\mathrm{p} 6 ; \mathrm{p} 1-\mathrm{p} 3$ are in the diencephalon and $\mathrm{p} 4-\mathrm{p} 6$ are in the secondary prosencephalon.

\section{Expression pattern of Dlx-1 and Dlx-2 (Tes-1)}

At E12.5 Dlx-I and Dlx-2 (Tes- 1$)$ show the same pattern of expression (Figs. $1 a-h, 2 a-f$ ). The only reproducible difference is that the hybridization signal is always greater with the $D l x-1$ probe, suggesting that there may be more $D l x-1$ than $D l x-2$ RNA in these cells. At E12.5, expression of these genes is principally detected within the head; in the forebrain, teeth anlage (Fig. $5 J$ ), retina (Fig. $5 J$, and facial ectoderm (data not shown), although at earlier ages they are also strongly expressed in the limb ectoderm, branchial arches, and cranial and spinal neural crest derivatives (Dollé et al., 1992; Bulfone et al., in press). Brief descriptions of $D l x$ gene expression in the developing teeth and vomeronasal organ have already been reported (Porteus et al., 1991; Robinson et al., 1991).

In the forebrain, there are two major domains of expression, which are separated by a zone of tissue in which expression of the genes is not detected (see Figs. 6, 7 for schematic representations of the results). In the telencephalon, the expression domain of $D l x-1$ and $D l x-2$ includes the medial ganglionic eminence (MGE), the lateral ganglionic eminence (LGE), and the septum (SE) (Figs. $1 a-h, 2 a-f, 3 b, 5 H, I$; for a complete list of anatomical abbreviations, see Table 1). The expression in the LGE stops before the sulcus that limits the eminence from the primordia of the cerebral cortex $(\mathrm{C})$. The entire neuroepithelium of the cerebral cortex, the caudal ganglionic eminence (CGE, Fig. $5 J$, and the caudoventrally adjacent eminentia thalami (EMT, Fig. 2b,e) are unlabeled. This zone of expression extends caudally (basally in the topological map, Fig. 7) from the SE, LGE, and MGE into a boundary domain in the stalk of the cerebral hemisphere (Fig. 6). The upper part of this boundary domain may be conceived of as an anterior entopeduncular area (AEP), and the lower part of this domain corresponds to the anterior preoptic area (POA), which reaches the rostral aspect of the optic stalk (Figs. $1 a-h, 2 c, f$ ). Medially, the $D l x$-positive domain is continuous with the lamina terminalis (Fig. $1 c, g$ ).

This rostral $D l x$-positive zone is bounded by a region where these genes are not expressed. This $D l x$-negative zone of expression can be defined as an "optoeminential zone"; it includes the CGE (Fig. 5J), the supraoptic/paraventricular area (SPV), the EMT (Figs. $1 d, h ; 2 b, e ; 5 J$ ), the anterior hypothalamus (AH) (Fig. 2b,e), and the posterior preoptic area (POP) (Figs. $1 d, h$; $2 \mathrm{c} f)$. These $D l x$-negative regions are seen in the sagittal sections in Figure 1 as a gap that tapers into the optic stalk paramedian area (see arrows in Fig. $1 a, c, d$ ), as well as a thin zone just caudal to the MGE and AEP (Fig. $1 d, h$ ). These zones are also apparent in the transverse (Fig. $2 b, c, e, f$ ) and coronal (Fig. $5 J$ ) sections. At the optic stalk, this zone consists of a short, thin strip of cells (see arrows in Fig. $1 a, c, d$ ). In some sections, there are as few

\footnotetext{
Figure 2. Comparison of $D l x-1, D l x-2, G b x-2$, and Wnt-3 expression using in situ RNA hybridization to E12.5 transverse sections. $E-G$ show cresyl violet-stained sections obtained from the same regions as the sections used for in situ RNA hybridization shown to their right. The positions of these sections are shown in Figure $1 A .{ }^{35}$ S-labeled riboprobes were used for all of these samples. They were photographed using bright-field microscopy; $a-l$ were photographed using dark-field microscopy. The abbreviations are defined in Table 1 . The arrow in $E$ shows the location of the zona limitans. $a-c$ were analyzed for $D l x-1$ expression; $d-f$, for $D l x-2$ (Tes- 1$) ; g-i$, for $G b x-2$; and $j-l$, for $W n t-3$. All of the sections were obtained from a single mouse embryo. The plane of these sections is not perfectly horizontal; the left side is slightly more dorsal than the right side. Thus, in some sections, different regions of the brain are seen on the left and right sides. For instance, the section in $b$ no longer has the EMT on its right side; this explains the asymmetry of $D l x$ expression in this panel, where the left side shows the $D l x$-negative EMT while the right side shows the $D l x$-positive AEP. A black line is drawn between the AEP and POA domains, from the apex of a ventricular ridge to an external furrow; this boundary corresponds to the hypothetical limit between $\mathrm{p} 5$ and $\mathrm{p} 6$. Note that $G b x-2$ expression ends abruptly at this boundary $(i)$. The section number for each panel is as follows: row $E: E(130), a(135), d(134), g(130), j(136)$; row $F: F(160), b(165), e(164), k(162) ;$ row $G$ : $G(190), c$ (195), $f(194), i(190), l(192)$. Scale bar, $1 \mathrm{~mm}$.
} 


\section{DIx-1}
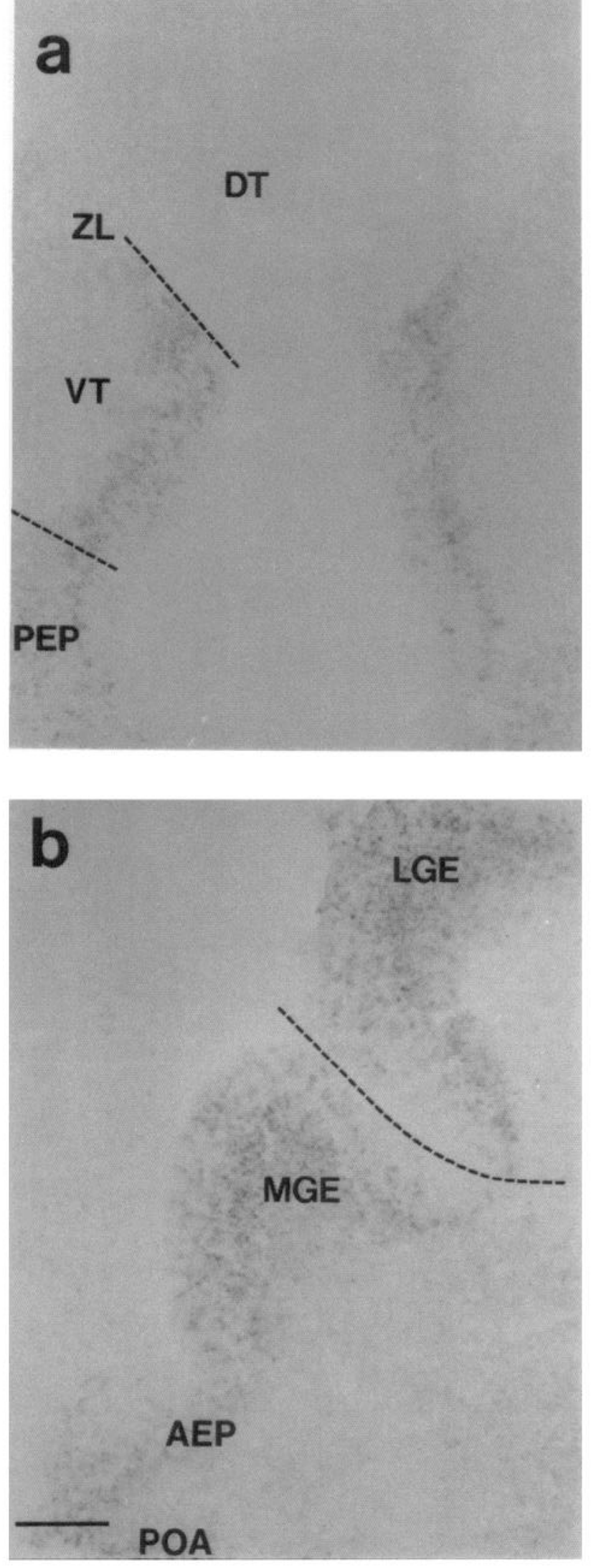

\section{Gbx-2}
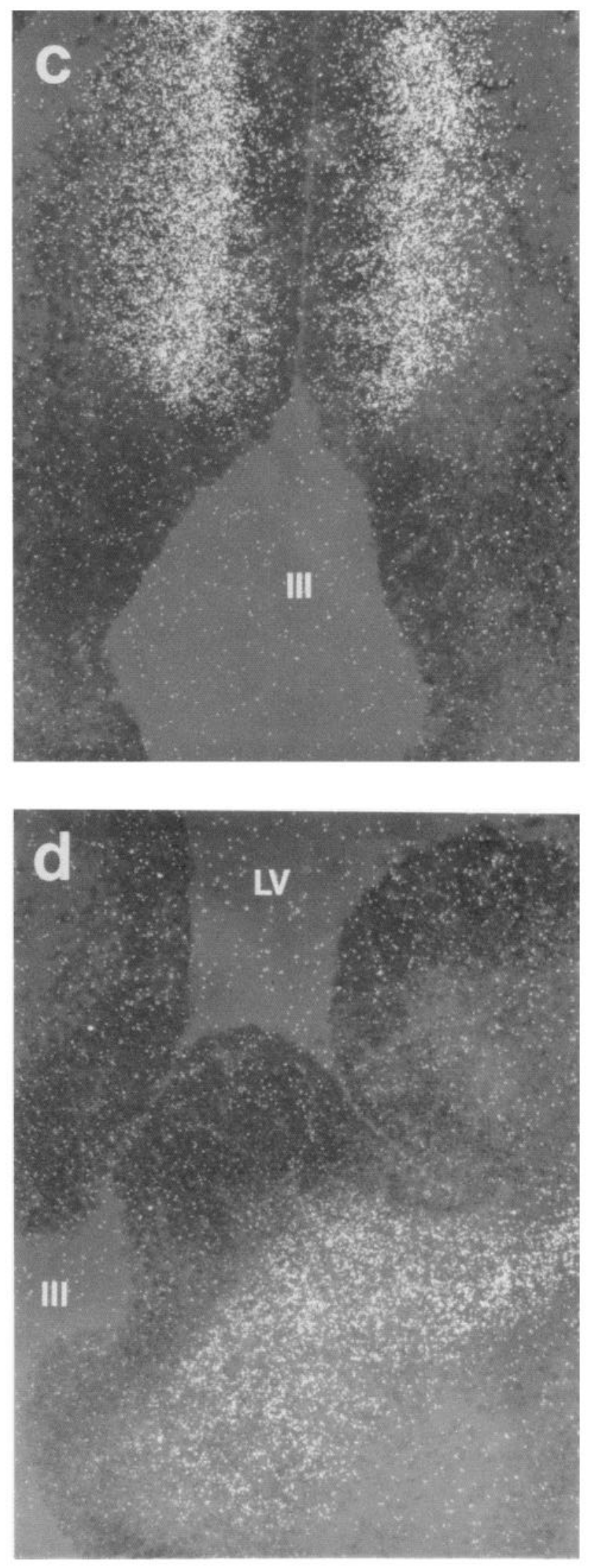
as approximately $10 D l x$-negative cells separating the $D l x$-positive zones (a low-magnification view of such a region is shown in Fig. $1 d$ ). Thus, although this gap in $D l x$ expression is always detected, it should be emphasized that because the gap can be extremely thin, it is possible that there might be a small region in which the rostral and caudal $D l x$-positive domains are connected.

Adjacent to the $D l x$-negative optoeminential region there is a second domain that strongly expresses both $D l x-1$ and $D l x$ 2. It extends from the posterior aspect of the optic stalk to the boundary at the zona limitans intrathalamica (the zona limitans is the boundary between p3 and p2). Expression is detected primarily in the alar zone of the secondary prosencephalon and rostral diencephalon. Within this alar longitudinal band, expression is found in the following regions (from rostral to caudal): suprachiasmatic area (SCH), hypothalamic cell cord (HCC), posterior entopeduncular area (PEP), and ventral thalamus (VT) (Figs. $1 a, c-e, g, h ; 2 a-f ; 5 J, K$ ). Thus, the caudal limit of expression of $D l x-1$ and $D l x-2$ is at the zona limitans intrathalamica, although occasional $D l x$-positive cells are found across the zona limitans intrathalamica in the dorsal thalamus (data not shown). At the zona limitans, there is a ventricular ridge which is characteristic of neuromeric structures in the hindbrain (Fig. $5 J$ ). In fact, ventricular ridges and external furrows can be seen at discrete locations along the longitudinal axis of the forebrain in Figure $5 J$. These structures may in fact correspond to the boundaries between the six hypothetical prosomeres. These boundaries are marked in Figure $5 J$ and this issue will be further addressed in Discussion.

Although most of $D l x$ expression is in the alar plate, there is one region where the $D l x$ genes appear to be expressed in the basal plate. This is in the lateral parts of the tuberal hypothalamus (TU), where there is weak Dlx expression (Figs. 1 a,d,e,h; $2 b, e)$. Furthermore, there is $D l x$ expression in the region of the boundary between the mammillary area (MA) and the TU (between $\mathrm{p} 4$ and p5) (Fig. 1d). However, due to the lateral bending of the alar plate over the basal plate in this part of the brain, the $D l x$-positive tissue might in fact be restricted to cells derived from the alar plate. In other neighboring basal and paramedian floor regions, such as the MA, median part of the TU, and retrochiasmatic area $(\mathrm{RCH})$, expression of the $D l x$ genes is not detected (Fig. $1 a-h$ ).

In the two $D l x$-positive domains, there are very few cells adjacent to the ventricle that express $D l x-1$ and $D l x-2$; those that do are frequently radially aligned (Fig. 3a,b). Extensive expression of these genes begins in a subventricular layer of cells and extends outward toward the pial surface; the strongest expression is found in this subventricular layer. Examination of the in situ hybridizations using the digoxigenin probes reveals that at least $90 \%$ of the cells in the subventricular layer are expressing $D l x-1$ and $D l x-2$ (data not shown).

\section{Expression patterns of $\mathrm{Gbx}-1$ and $\mathrm{Gbx}-2$}

The $G b x$ genes described in this study were initially isolated as part of a screen for homeobox-containing genes expressed in the gastrulating embryo (M. A. Frohman, G. R. Martin, and D. Kimelman, unpublished observations). $G b x-1$ and $G b x-2$ are located on chromosomes 5 and 1, respectively (Frohman et al., in press). These genes are related to Chox-7 (Fainsod and Greunbaum, 1989), and portions of their homeodomains have previously been reported; $G b x-1$ corresponds to $M M O x-B$ and $G b x-2$ corresponds to $M M O X-A$ (Murtha et al., 1991).

RNA in situ hybridization analysis of mouse embryos at various developmental stages between E6.5 and E1 1.5 has shown that $G b x-1$ mRNA is detected at low levels only in the E11.5 forebrain (Frohman and Martin, unpublished observations). In the present study we were unable to detect $G b x-1$ RNA in the E12.5 mouse brain. In contrast, expression of $G h x-2$ RNA is first detected during gastrulation, shortly after the beginning of mesoderm formation. During neurulation (E7.5-E8.5), $G b x-2$ expression is restricted to the neural ectoderm and underlying mesoderm, with a rostral boundary in the region of the midbrain-hindbrain junction. By E9.5, $G b x-2$ expression is detected in a number of distinct sites including the spinal cord, hindbrain, optic vesicle, and the mandibular arch (Frohman and Martin, unpublished observations).

By E12.5, several de novo sites of expression of $G b x-2$ are observed in the forebrain, and expression is not detected outside the CNS. In the E12.5 CNS, $G b x-2$ is expressed in four domains: the spinal cord, the hindbrain, the dorsal thalamus, and the basal telencephalon (Figs. 6, 7). In the spinal cord, there is uniform expression in both alar and basal plates. There appcars to be much less or no expression in a thin longitudinal band in the intermediate zone; the floor and roof plates are also devoid of expression (Fig. $1 i-l$ ). This domain of expression continues into the hindbrain, with its rostral end approximately in the region derived from rhombomere r6 (Fig. $1 i-l$ ). In the medulla, the basal plate (motor structures) seems to be less intensely labeled (Fig. $1 i-l$ ), but the alar plate [sensory structures, probably the trigeminal sensory columns (TSC)] remains clearly positive (Fig. $4 a$ ).

More rostrally, a second area expressing $G b x-2$ is observed laterally in the alar plate approximately in the region of rhombomeres $\mathrm{r} 3$ and $\mathrm{r} 2$ (Figs. $1 i, l ; 4 a$ ). The location of these domains was deduced by their position relative to motor nuclei and nerve roots visualized in cresyl violet-stained sections. These cells may be part of the TSC. Weak expression is also apparent in the adjacent basal region. The regions derived from rhombomere $\mathrm{rl}$, the isthmus (Is), and the mesencephalon (M) do not show expression (Fig. $1 i-l$ ).

The third zone of $G b x-2$ expression is in the diencephalon. $G b x-2$ is expressed in the prospective dorsal thalamus, which

Figure 3. Comparison of $D l x-1$ and $G b x-2$ expression in adjacent domains of the diencephalon and telencephalon using $i n$ situ RNA hybridization to E12.5 transverse sections. $a$ and $b$ show transverse sections 136 and 196 , which were hybridized with a digoxigenin-labeled riboprobe made from the $D l x-1$ cDNA. $c$ and $d$ show transverse sections 130 and 190 , which were hybridized with a ${ }^{35}$-labeled riboprobe made from the $G b x-2$ cDNA. The broken lines in $a$ show the location for the ZL and the boundary between the VT and the PEP. The broken line in $b$ shows the location of the boundary between the MGE and LGE. The abbreviations are defined in Table 1. Dark-field and epifluorescence photomicroscopy was used in $c$ and $d$ to show the silver grains and the methyl green counterstain simultaneously. Bright-field microscopy was used in $a$ and $b$. Scale bar, $100 \mu \mathrm{m}$. 


\section{Gbx-2}
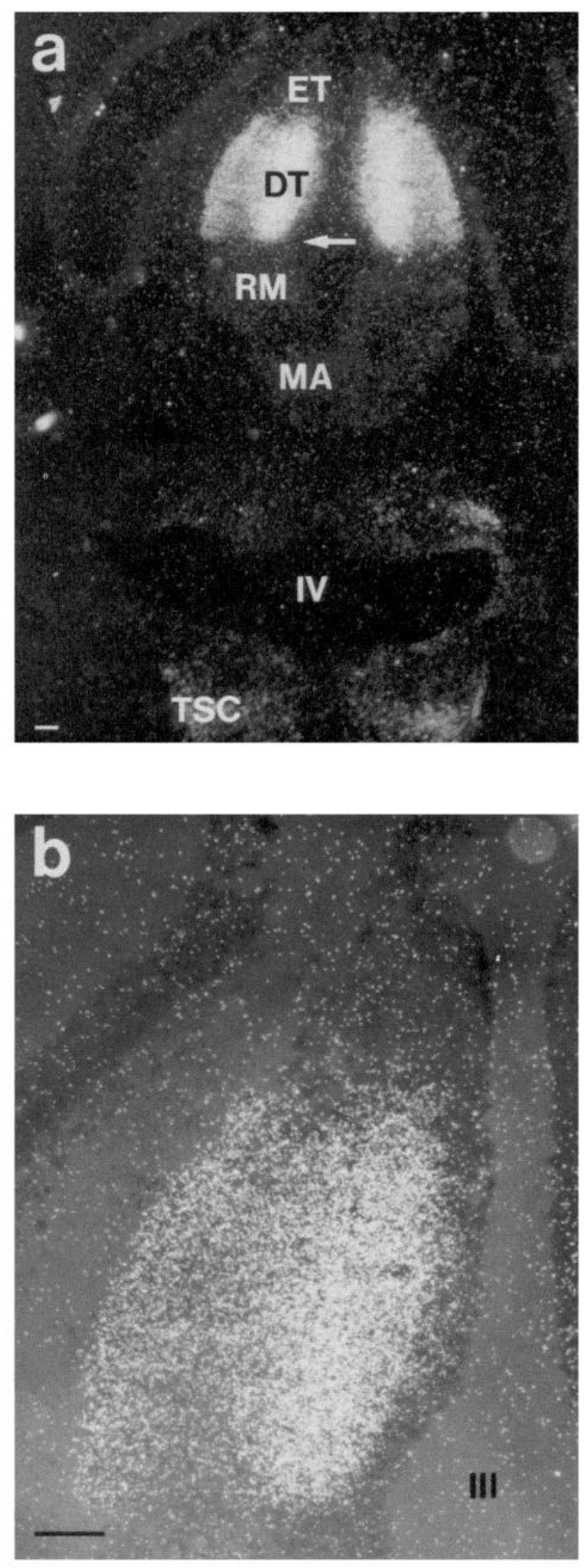

Wnt-3
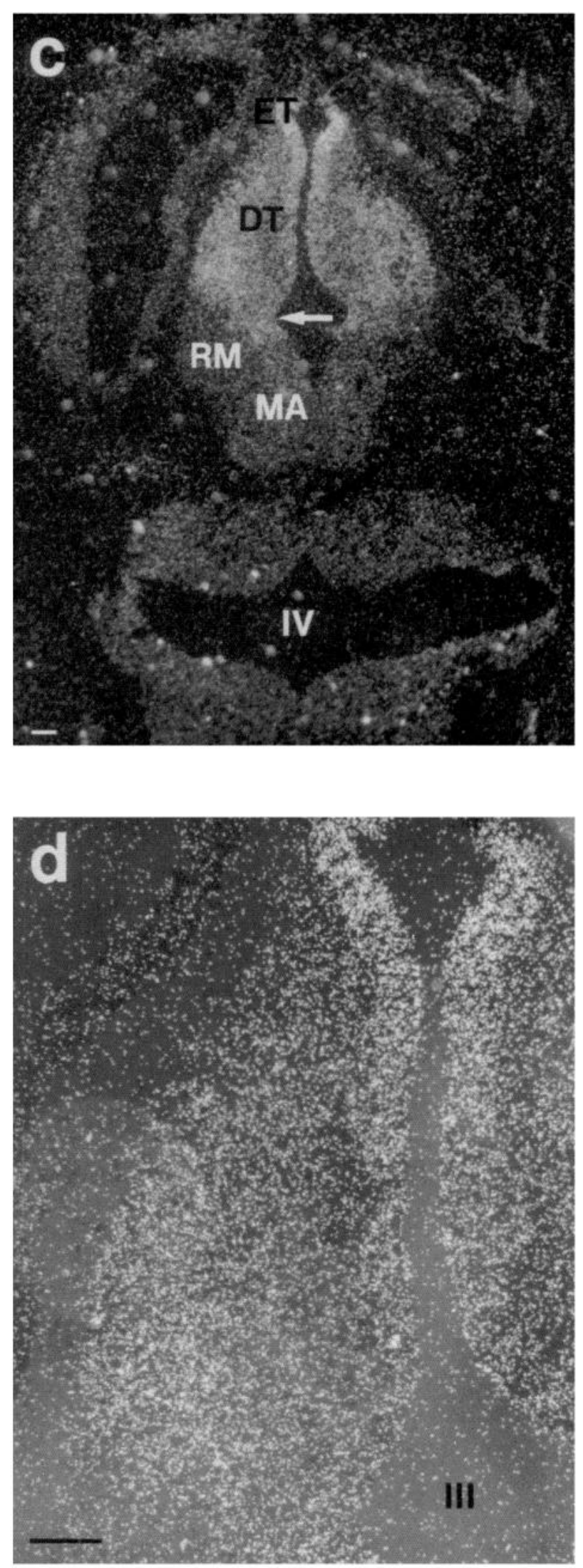

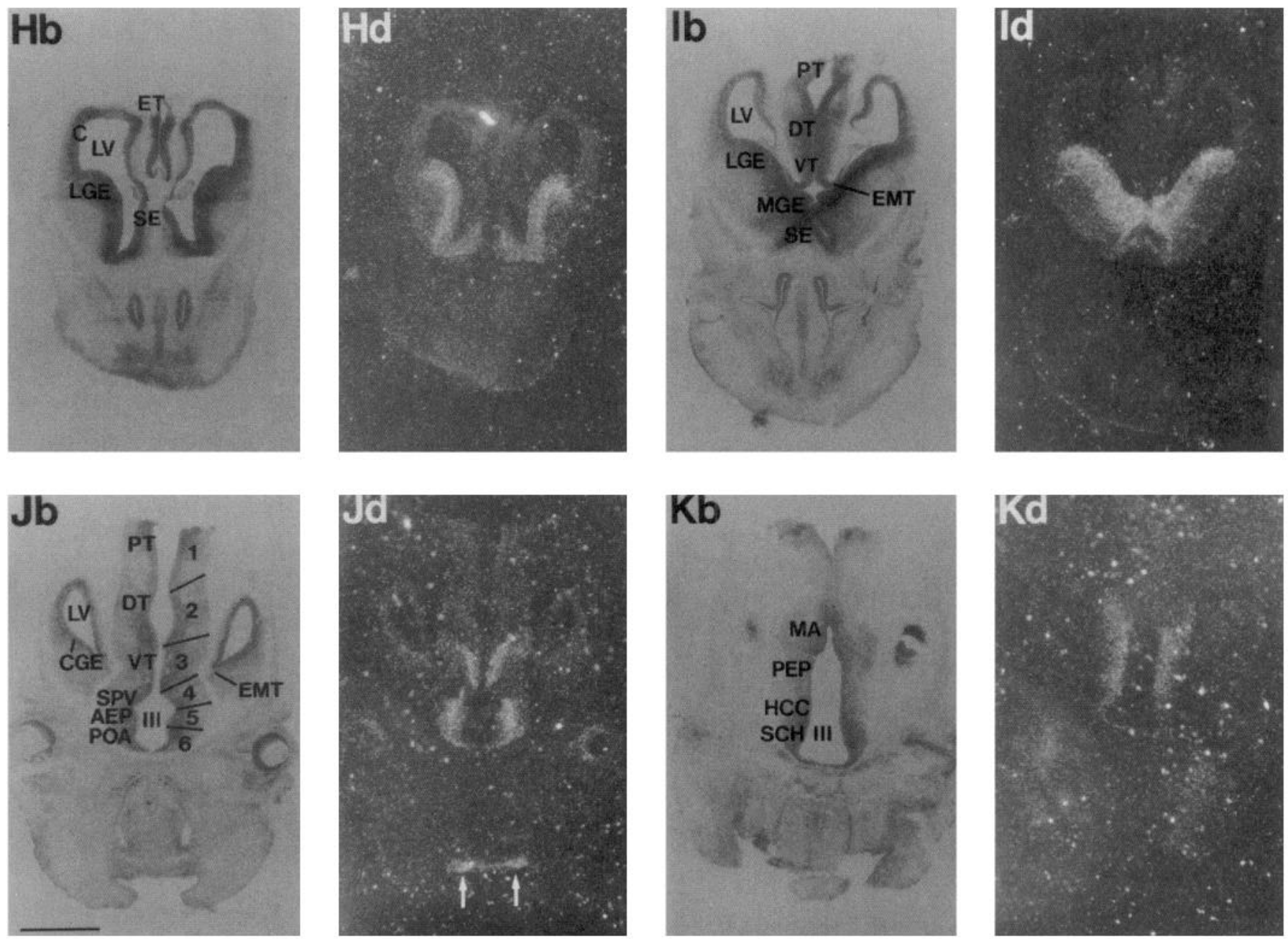

Figure 5. Dlx-2 expression in coronal sections of E12.5 mouse embryo heads using in situ RNA hybridization. Coronal sections from a single embryo were probed with the a ${ }^{35}$ S-labeled $D l x$-2 riboprobe (see Fig. $1 A$ for the location of $\left.H-K\right)$. Following dark-field photography $(d)$, the samples were counterstained with cresyl violet and photographed in bright-field $(b)$. The arrows in $J d$ correspond to expression in the developing teeth. The abbreviations are defined in Table 1 . The section number for each panel is as follows: $H, 32 ; I, 52 ; J, 72 ; K, 90$. Scale bar, $1 \mathrm{~mm}$.

is part of the alar domain of the $\mathrm{p} 2$ segment. $G b x-2$ expression does not extend dorsally into the epithalamus, or ventrally to the alar/basal boundary. The caudal boundary abuts on the pretectum (alar p1), and the rostral boundary is at the zona limitans, which separates the dorsal thalamus (alar p2) from the ventral thalamus (alar p3) (Figs. $1 i-l ; 2 g ; 3 c ; 4 a, b$ ) (see Figs. 6, 7 for the location of alar p1, p2, p3). It is important to emphasize that $G b x-2$ expression within the dorsal thalamus abuts, but does not appear to overlap, the zone of $D l x-1$ and $D l x-2$ expression in the ventral thalamus (Figs. $1 a-l ; 3 a, c$ ).

Like the $D l x$ genes, $G b x-2$ is primarily expressed in cells in the subventricular and mantle layers within the wall of the diencephalon (Figs. $2 g, 3 c ; 4 a, b$ ). In fact, the transverse (Fig. $4 a, b$ ) and coronal (data not shown) sections show that the $G b x-2$ expression pattern defines four zones in the dorsal diencephalon wall: (1) the ventricular zone, which has very little or no expression; (2) a subventricular zone, which exhibits strong expression; (3) an intermediate mantle zone, which has weak expression; and (4) a superficial mantle zone, which has strong expression.

The fourth transverse region of $G b x-2$ expression is in the basal telencephalon. These $G b x$-2-positive cells are centered in the mantle of the rostralmost part of the MGE and AEP (Figs. $1 l, 2 i, 3 d)$. Figures $2 i$ and $3 d$ show a thin dorsolateral extension of the positive MGE mantle zone, toward the mantle zone of the LGE. The curvature of this boundary may represent the

Figure 4: Comparison of $G b x-2$ and Wnt-3 expression in the diencephalon using in situ RNA hybridization to E12.5 transverse sections. The position of these sections is indicated in Figure $1 A$ by the number 4. $a$ and $b$ show low- and high-magnification views of a transverse section (section 100 ), which was analyzed for $G b x-2$ expression. $c$ and $d$ show low- and high-magnification views of a transverse section (section 102), which was analyzed for $W n t-3$ expression. ${ }^{35}$ S-labeled riboprobes were used for all of these samples. The abbreviations are defined in Table 1 . The arrows in $a$ and $c$ show the location of the subthalamic sulcus. Sections through the pons and medulla are seen below the forebrain in $a$ and $c$. Dark-field microscopy was used in $a$ and $c$; dark-field and epifluorescence microscopy was used in $b$ and $d$ to show the silver grains and the methyl green counterstain simultaneously. Scale bars, $100 \mu \mathrm{m}$. 


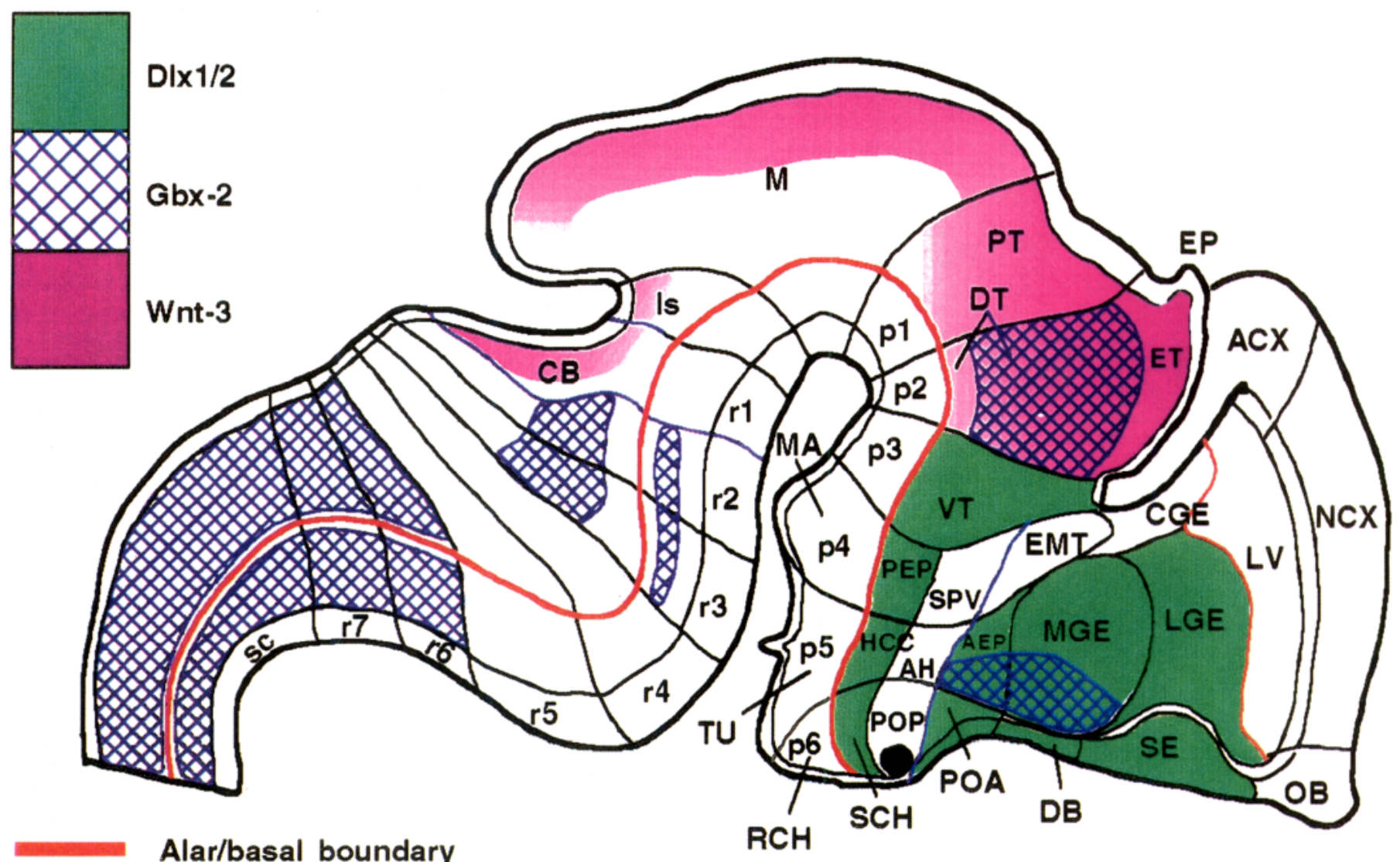

\section{(longitudinal axis)}

Figure 6. Realistic map of the expression patterns of the $D l x-1, D l x-2, G b x-2$, and $W n t-3$ genes in the brain of an E12.5 mouse. This figure shows a schematic medial view of the brain of an E12.5 mouse. The medial wall of the telencephalon is opened to show the internal ganglionic eminences. The transverse (neuromeric) subdivisions are delineated by solid lines that are perpendicular to the principal longitudinal subdivision that divides the alar and basal zones, and defines the longitudinal axis of the brain (shown by a red line). Other longitudinal zones are delimited by black lines that are parallel to the longitudinal axis. Four longitudinal zones are shown in the spinal cord; from dorsal to ventral they are the roof plate, alar plate, basal plate, and floor plate. These four zones extend rostrally. See Table 1 for the definitions of the letter codes. The rhombomeres ( $r 1-r 7)$ and theoretical prosomeres $(p 1-p 6)$ are labeled in the floor plate domains of their neuromeres. The expression patterns of the genes studied in this article are shown in the following colors: Dlx-1 and -2, green; Gbx-2, purple; Wnt-3, magenta. The Wnt-3 expression is shown as a D-V gradient. The site of the optic stalk is indicated by the black circle in the POP domain.

Figure 7. Topologic map of the expression patterns of the $D l x-1, D l x-2, G b x-2$, and $W n t-3$ genes in the brain of an E12.5 mouse. In this figure, the longitudinal axis of the brain has been deconvoluted, and the transverse and longitudinal domains are delineated by black lines (the organization of the region rostral to the rhombencephalon is theoretical). The longitudinal boundary that separates the alar and basal regions is shown as a red horizontal line that extends from the spinal cord to the end of the secondary prosencephalon. Further longitudinal subdivisions within specific transverse domains are illustrated. For instance, within the p2, four longitudinal domains are illustrated, that are based upon the expression patterns of the $W n t-3$ and $G b x-2$. See Table 1 for the definitions of the letter codes. The expression pattern of the genes studied in this article are shown in the following colors: $D l x-1$ and -2, green; Gbx-2, purple $;$ Wnt-3, magenta. The D-V gradient of Wnt-3 expression is approximated. The positions of the rhombencephalon, mesencephalon, diencephalon, and secondary prosencephalon (which contains the telencephalon in its alar longitudinal tiers beginning with the EMT, AEP, POA layer) are indicated above the diagram. The locations of the rhombomeres and theoretical prosomeres are shown below the diagram. The optic stalk is represented by a black oval within the POP domain. The position of the CH, EP, and IN are shown. The horizontal dotted line in TU represents the observed Dlx expression in lateral parts of TU; in this region we are not certain whether $D l x$ expression extends into the basal domain. The caudal boundary of the Gbx-2 expression in p5 is not known with precision. Bottom, The longitudinal expression patterns of several genes, based upon our interpretation of the data presented by others. These data are compared to the neuromeric model. The expression of each of these genes is consistent with there being discontinuities at the boundaries of the theoretical prosomeres. The expression of most of these genes is also spatially restricted along the transverse axis; because of constraints on space, we have not shown these longitudinal domains in the figure. For some genes, the pattern of expression changes with time; thus, the results shown in this figure were taken from the following time points: Pax $[z f-a], 24 \mathrm{hr}$; Pax/zf-b], $24 \mathrm{hr} ;$ Pax-6, E11.5; Pax-7, E10; Pax-3, E10; Pax-2, E11; Wnt-1, E12.5/E14.5; Wnt-3a, E11.5; Wnt-5a, E9.5; Wnt-7b, E9.5; Plp (dm20), E10; Emx-1/Emx-2, E9.5; Otx-1/Otx-2, E9.75-E10.25; Nkx-2.1, E12.5; Nkx-2.2, E12.5; heir-1, E12.5; $N$-myc, E12.5; Bf-1, E11.5; Dlx-1/Dlx-2, E12.5; Gbx-2, E12.5. The references for these genes are found in the text. Expression domains caudal to the hindbrain are not shown. Some of the genes (Pax $[z f-b], E m x-2, W n t-1$, and $7 A)$ have additional domains of expression in the brain that are not shown. The vertical bars on the $W n t-1$ and $3 A$ lines correspond to transverse bands of expression at the Is/M and p2/p 3 boundaries, respectively. 

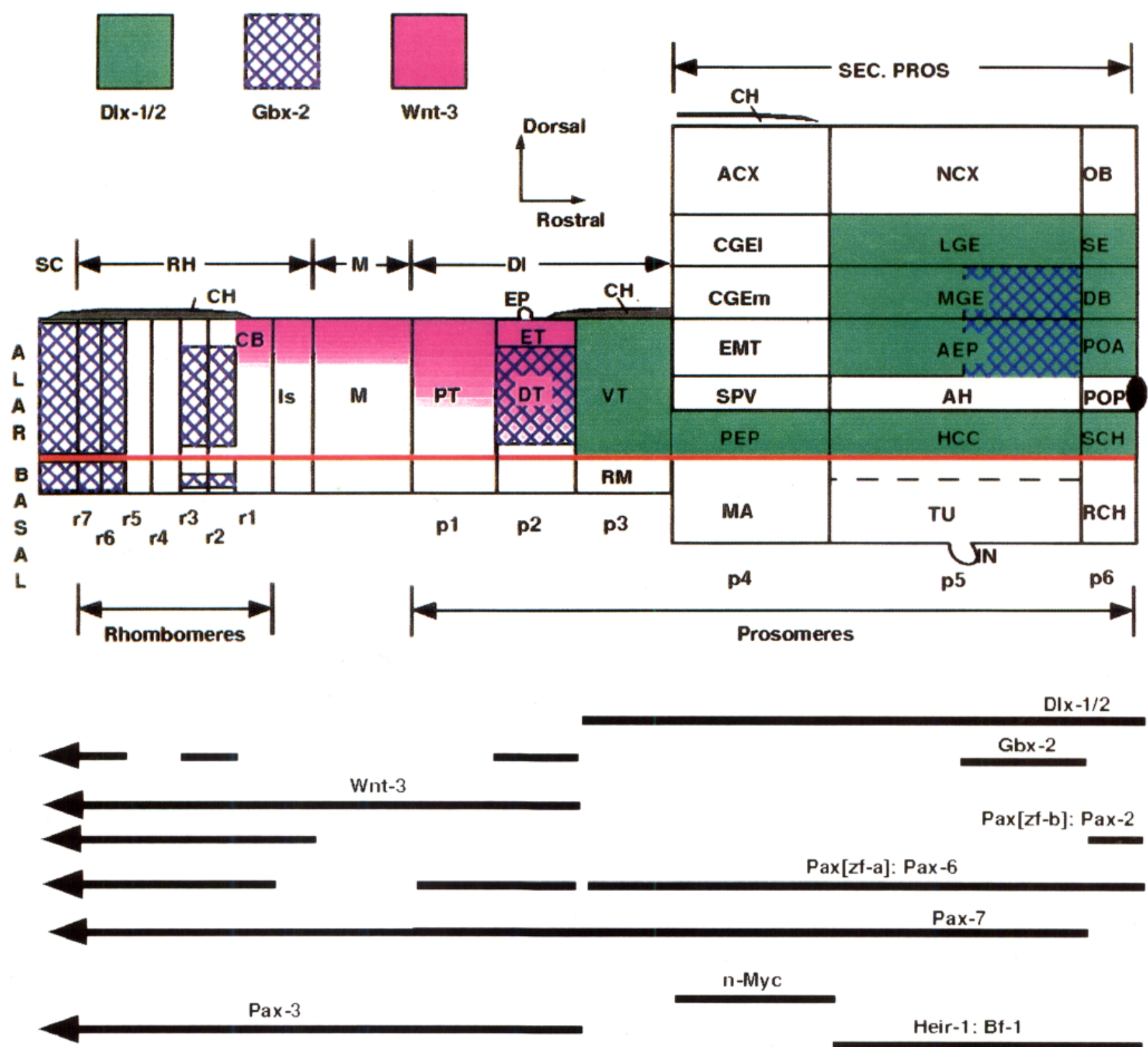

Heir-1: Bt-1

Emx-1: Emx-2: Nkx-2.1

Otx-1

Otx-2

Nkx-2.2

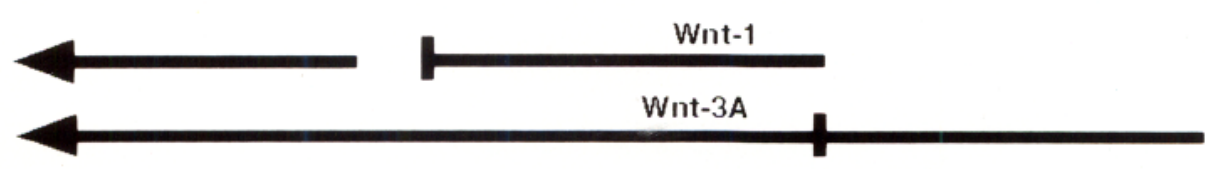

Wnt-5A

$\frac{\text { Wnt-7B }}{\operatorname{plp}(\mathrm{dm} 20)}$


Table 1. List of anatomical abbreviations

ACX Archicortex

AEP Anterior entopeduncular area

AH Anterior hypothalamus

ASC Alar spinal cord

$\mathrm{AQ}$ Aqueduct

BSC Basal spinal cord

C Cerebral cortex primordia

CB Cerebellum

CGE Caudal ganglionic eminence (1, lateral; m, medial)

$\mathrm{CH}$ Chorioid plexus

DB Diagonal band

DI Diencephalon

DT Dorsal thalamus

EMT Eminentia thalami

EP Epiphysis

ET Epithalamus

HB Hindbrain

HC Hippocampal primordium

HCC Hypothalamic cell cord

III Third ventricle

IN Infundibulum

Is Isthmus of mesencephalon

IV Fourth ventricle

LGE Lateral ganglionic eminence

LT Lamina terminalis

LV Lateral ventricle

MA Mammillary area, basal zone of $\mathrm{p} 4$

M Mesencephalon

MGE Medial ganglionic eminence

NCX Neocortex

OB Olfactory bulb

OR Optic recess

OS Optic stalk

p1-p6 Prosomeres 1-6

PEP Posterior entopeduncular area

POA Anterior preoptic area

POP Posterior preoptic area

PT Pretectum

r1-r7 Rhombomeres 1-7

$\mathrm{RCH}$ Retrochiasmatic area, basal zone of $\mathrm{p} 6$

RH Rhombencephalon

RM Retromammillary area, basal zone of $\mathrm{p} 3$

RP Rathke's pouch

sc Spinal cord

SE Septum

$\mathrm{SCH}$ Suprachiasmatic area

SOC Supraoptic commissura

SPV Supraoptic/paraventricular area

T Tectum

TR Tractus retroflexus

TSC Trigeminal sensory columns

TU Tuberal hypothalamus, basal zone of $\mathrm{p} 5$

VT Ventral thalamus

ZL Zona limitans

curvature of the sulcal boundary between the MGE and the LGE (Fig. 3b,d). The caudomedial boundary of expression ends abruptly at the boundary between the AEP and the POA, which we conceive of as the p5/p6 limit (Figs. $2 i, 3 d$ ). This $G b x-2-$ positive area, which is included within the alar secondary prosencephalon (Figs. 6, 7), may correspond to the anlage of the nucleus basalis or pallidus or both. Note that here, too, the $D l x$ genes and $G b x-2$ are expressed in a complementary pattern: $D l x-1$ and $D l x-2$ are expressed in the subventricular stratum of the MGE and AEP, whereas $G b x-2$ is expressed in the adjacent mantle (Figs. $2 c, f, i ; 3 b, d$ ).

\section{Expression pattern of $\mathrm{Wnt}-3$}

The pattern of $W n t-3$ expression in E10.5, E11.5, and E12.5 mouse embryos has previously been published (Roelink and Nusse, 1991). Their study showed that $W n t-3$ is expressed in the dorsal thalamus. This result suggested that a reexamination of the expression of this gene with respect to the expression patterns of $D l x-1, D l x-2$, and $G b x-2$ would be informative.

We have confirmed and extended the study of Roelink and Nusse (1991) by examining the expression of $W n t-3$ in three planes of section at E12.5. Strong expression is seen in the surface ectoderm of several regions of the body, including the mandibular arch, the frontonasal prominence, and the genital tubercle (data not shown). Within the CNS, Wnt-3 is expressed along the entire longitudinal axis except it is not expressed in the telencephalon; its rostral limit is in the diencephalon at the zona limitans (Figs. $1 m-p ; 2 j ; 4 c, d ; 6 ; 7$ ). It is expressed in the alar territories of the dorsal thalamus, pretectum, continuing caudally along a dorsal median and paramedian strip through the mesencephalon into the cerebellum (Figs. $1 m-p ; 2 j ; 4 c, d ; 6$; $7)$. In the wall of the neural tube, it is expressed both in the ventricular zone and in the mantle (Figs. $2 j ; 4 c, d$ ).

$W n t-3$ expression generally follows a $\mathrm{D}-\mathrm{V}$ gradient. For instance, within $\mathrm{p} 2$, it is most strongly expressed in the ventricular cells near the dorsal midline and extends ventrally in a decreasing gradient to fill the entire alar plate (Fig. $4 c, d$ ). It is, however, not expressed in non-neural roof structures like the epiphysis (Figs. $10,4 c$ ) and the tela chorioidea of the III and IV ventricles (Fig. $1 m-p$ ). The D-V gradient is also illustrated in Figure $1 n$, where the epithalamus (see arrow) is more strongly labeled than the dorsal thalamus. The $\mathrm{D}-\mathrm{V}$ gradient is also present in the pretectum and in the cerebellar primordia. In the cerebellar primordia, the highest expression is found at the rhombic lip and the level of expression gradually decreases toward the sulcus limitans (data not shown).

Compared to other brain regions, $W n t-3$ expression is most extensive in alar $\mathrm{p} 2$, where $G b x-2$ is also expressed. Thus, the expression domains of $W n t-3$ and $G b x-2$ share transverse boundaries at two potential interneuromeric limits. First, they both have sharp limits at the boundary separating the dorsal thalamus (alar p2) and the pretectum (alar p1) (Fig. $1 i, m$ ). Note that although $W n t-3$ expression in the mantle respects this boundary, expression within the ventricular zone does continue into the pretectum. They also share the boundary at the zona limitans, which separates the dorsal thalamus (alar p2) from the ventral thalamus (alar p3) (Fig. 1, best seen by comparing $k$ and $o$; Fig. $2 g, j$ ).

Although $W n t-3$ and $G b x-2$ share transverse borders, their expression patterns differ along the $\mathrm{D}-\mathrm{V}$ axis of the alar $\mathrm{p} 2$ region (a domain that contains the dorsal thalamus and the epithalamus). Figure 4 illustrates the expression of these genes in a transverse plane. The $W n t-3$-positive area extends ventrally below the subthalamic sulcus, whereas the expression domain of $G b x-2$ ends ventrally at the subthalamic sulcus (see arrow). At this level, the ventral boundary of $W n t-3$ expression probably 
limits the alar dorsal thalamus from the basal region of its own neuromere. Thus, the ventral boundary of $G b x-2$ expression does not coincide with the ventral boundary of the alar plate.

As noted above, the $W n t-3$ gene is expressed ventrally beyond the subthalamic sulcus, which some authors consider as the rostral continuation of the sulcus limitans of the caudal brainstem, and thus as a boundary of the alar (dorsal) and the basal (ventral) plates. The data showing $W n t-3$ expression slightly ventral to the sulcus can be interpreted in two ways. If the sulcus is the boundary between the alar and basal plates, then $W n t-3$ expression crosses this boundary and is expressed in a dorsal zone of the basal plate. Alternatively, the sulcus does not delimit the alar/basal boundary, and the ventral extent of $W n t-3$ expression possibly defines the alar/basal boundary. Although both interpretations are possible, we prefer the lattcr becausc a comparison shows that the ventral extent of the $D l x$ genes in the ventral thalamus coincides with the ventral extent of $W n t-3$ expression in the dorsal thalamus (see Fig. 1d,h,p).

The dorsal boundaries of $W n t-3$ and $G b x-2$ expression also differ in alar p2. Wnt-3 is expressed up to the most dorsal domain of $\mathrm{p} 2$, the epithalamus (primordia of the habenula). By contrast, $G b x-2$ is not expressed as far dorsally, showing a sharp longitudinal boundary at the limit between the dorsal thalamus and the epithalamus (Figs. $1 i-p ; 4 a-d$ ).

Within the region of alar $\mathrm{p} 2$, where the expression of $W n t-3$ and $G b x$ - 2 overlap, their expression also shows some differential features along the M-L axis (Figs. $2 g, j ; 4 a-d$ ). Whereas $W n t-3$ is expressed in both the ventricular and mantle zones, $G b x-2$ is expressed primarily in the mantle. Furthermore, the highest levels of $G b x-2$ expression are found in two distinct zones of the dorsal thalamic mantlc, one deep and the other superficial. $W n t-3$ is expressed more uniformly through the mantle, except in the deep zone, where there is less $W n t-3$ expression (Figs. $2 g, j ; 4 b, d)$. This deep zone is where $G b x-2$ expression is the strongest.

Thus, $W n t-3$ has a more extensive pattern of expression in p2 than $G b x-2$; it is expressed in both the ventricular zone and in the mantle along a wider dorsoventral region within the putative neuromere, comprising its entire alar plate. $G b x-2$ is restricted to a subset of deep and superficial dorsal thalamic primordia, and is excluded from both the epithalamus and the ventralmost part of the dorsal thalamus.

\section{Discussion}

We have described the expression patterns at E12.5 of four genes, $D l x-1, D l x-2, G b x-2$, and $W n t-3$, that are evolutionarily related to genes known to play a rolc in controlling the development of the Drosophila body plan. In the forebrain, the expression patterns of these genes define domains delimited by sharp boundaries. These boundaries are reproducibly found at the same positions at E12.5 in each of the six different embryos that we have analyzed. Furthermore, analysis at earlier stages also shows essentially the same patterns of expression ( Dlx -2 from E9.5 to E11.5, Bulfone et al., in press; $G b x-2$ at E11.5, C. Esmurdoc, A. Bulfone, and J. L. R. Rubenstein, unpublished observations; Wnt-3 from E10.5 to E11.5, Roelink and Nusse, 1991; Dlx-1 at E10.5, Dollé et al., 1992).

At most of the expression boundaries, RNA transcripts from these genes are restricted to cells on one side of the boundary. The mechanism(s) that maintains these patterns is not known, although there are two possibilities. First, there may be restrictions to cell migration at these boundaries that prevent mixing of cells between different domains. Such restrictions to cell migration are present between hindbrain segments (Fraser et al., 1990), where there are analogous sharp expression boundaries of the Hox genes and Krox 20 genes (Hunt et al., 1991). Another possibility is that cells can cross the boundaries but, once they do, the expression from these genes is turned off. However, for this to be the case, the half-life of their RNAs, once the cells migrate into the nonexpressing domain, would have to be extremely short, otherwise analysis using in situ RNA hybridization would detect a gradient of expression rather than a sharp boundary. We favor the former hypothesis, because this is the process found in the hindbrain. This point of view is strengthened because some of these expression boundaries are coincident with morphological structures, such as ventricular ridges and external furrows, that are perpendicular to the longitudinal axis, similar to those seen in the hindbrain (see Fig. 5). These results lead us to hypothesize that like the hindbrain, the forebrain is organized into neuromeres, and that the gene expression domains described here provide markers for this segmental organization. Moreover, considering that these genes apparently encode transcription factors and a secreted signaling molecule, it is reasonable to suggest that they play a role in controlling the specification and differentiation of the proposed forebrain segments.

\section{Expression patterns of $D / x-1, D / x-2, G b x-2$, and Wnt-3}

$D l x-1$ and $D l x-2$ are two members of a newly discovered homeobox gene family (Porteus et al., 1991; Price et al., 1991; Robinson et al., 1991) that are homologs of the Drosophila Dll gene (Cohen et al., 1989). Robinson et al. (1991) have evidence that therc arc two other members of $D l x$ gene family $(D l x-3$ and $D l x-4)$. Dlx-2 maps near the Hox-4 cluster on mouse chromosome 2 (Özçelik et al., 1992), and pulse-field gel electrophoresis shows that $D l x-1$ and $D l x-2$ map within $50 \mathrm{~kb}$ of each other (McGuinness et al., 1992). Our results, which are the first experiments to compare directly the expression pattern of $D l x-1$ and $D l x-2$, are focused upon their expression in the E12.5 mouse brain, and have expanded upon previous reports by our group (Porteus et al., 1991) and two others (Price et al., 1991, 1992; Robinson et al., 1991). At this stage in development, no differences in the pattern of expression of $D l x-1$ and $D l x-2$ in the forebrain are detected. Both genes are expressed in two domains in the forebrain, separated by the optoeminential zone where the $D l x$ genes are not expressed (see Results and Figs. 6, 7). Within the wall of the neural tube, $D l x$ gene expression is largely limited to a subventricular layer. In this zone, most if not all of the cells express both of thesc genes (sec Fig. $3 a, b$ for $D l x-1$; $D l x-2$ data are not shown), suggesting that individual cells express both $D l x-1$ and $D l x-2$. Presently, we are investigating whether the cells in this layer are mitotically active.

The adult structures derived from the $D l x$-positive domains are not precisely known. The rostral domain (SE, DB, LGE, MGE, AEP, and POA) probably gives rise to such structures as the striatal, pallidal, basal, septal, diagonal band and anterior preoptic nuclei. The caudal domain ( $\mathrm{SCH}, \mathrm{HCC}$, lateral TU, PEP, and VT) probably gives rise to a number of structures including the suprachiasmatic and other anterior hypothalamic nuclei, as well as ventral thalamic derivatives like the zona incerta and the reticular and ventral geniculate nuclei. The interposed $D l x$-negative optoeminential zone includes derivatives of the CGE and EMT (the amygdala/bed nucleus of the stria terminalis complex), as well as a number of anterior hypotha- 
lamic, supraoptic/paraventricular, and posterior preoptic nuclei.

In general, the regions of the E12.5 brain that express the $D l x$ genes are sharply delimited from $D l x$-negative zones. Thus, at these boundaries, strongly expressing cells are next to cells that apparently express much less or no $D l x$ mRNA. These boundaries occur in several places. For instance, between the LGE and the neocortical primordia (Figs. $2 a-f, 5 H$ ) there is a sharp transition near to, but not at, the sulcus that morphologically separates these structures. Sulci are frequently used as landmarks for the boundaries between different neuronal domains. It may be that the expression patterns of genes, like the $D l x$ genes, may more accuratcly demonstrate the boundary between distinct neuronal structures than do sulci. Caudally, at the zona limitans, there is also a sharp boundary of $D l x$ gene expression between the ventral thalamus and dorsal thalamus (see Fig. $3 a$; see also Figs. $1 a-h ; 2 a, d ; 5 J)$. This boundary coincides with a ventricular ridge and external furrow (Fig. $5 J$ ), rather than with a sulcus (sulcus medius thalami) reported by others (Herrick, 1910; Kuhlenbeck, 1973). The $G b x-2$ and $W n t-3$ genes, which are expressed in the dorsal thalamus, also show a sharp limit at the zona limitans at the same ventricular ridge (see Figs. $1 i-p$; $2 g, j ; 3 c)$. Of note, the $W n t-3 a$ gene appears to have a discrete zone of expression along this ventricular ridge (Roelink and Nusse, 1991).

In the forebrain, the expression of $G b x$-2 (which has not been previously reported) is related topologically to the expression of the $D l x$ genes in two regions (Fig. 3). As mentioned above, there is a sharp border at the zona limitans, between the expression of $G b x-2$ in the dorsal thalamus and the expression of the $D l x$ genes in the ventral thalamus. $G b x-2$ is also expressed in the basal forebrain in a superficial mantle zone of the MGE and adjacent AEP (Figs. $1 l, 2 i, 3 d$ ). In the MGE, the $D l x$ genes are expressed in the differentiating cells of the subventricular zone, whereas $G b x-2$ is expressed in a relatively small domain of more mature cells at the base of the eminence. There is not a clear morphologic boundary separating the $D l x$-positive zone from the $G b x-2$-positive zone, although histologically the $G b x$ 2 -positive zone differs from the rest of the ganglionic eminence in that it has a lower cell density. It appears that there is no overlap between the $D l x$ - and $G b x$-2-positive zones, although at the resolution of these experiments we cannot exclude the possibility that there is some mixing of $D l x$-and $G b x$-2-positive cells at the boundaries of these regions.

The adult ncuronal structures that derive from the embryonic domains where the $G b x-2$ gene is expressed are not known with certainty. Our preliminary assignments for the spinal cord, medulla, and pons have been mentioned in Results. The extensive expression in the dorsal thalamus suggests that $G b x-2$ may have a role in the development of this central relay/processing station. The significance of its bilaminar pattern of expression within the wall of the dorsal thalamus is discussed below. Finally, the basal telencephalon domain may be the anlage for the nucleus basalis or pallidus or both. The nucleus basalis is more probable since this region coincides with the area containing early-appearing AChE-expressing neurons in the rat beginning at E12.5 (Fernandez, Caballero-Blada, and L. Puelles, unpublished observations).

Like the $D l x$ genes, $G b x-2$ is primarily expressed in the mantle. There is little or no expression in the cells adjacent to the ventricle, although our data do not demonstrate with certainty whether $G b x-2$ is expressed in limited numbers of ventricular zone cells, in the manner that the $D l x$ genes are. In the dorsal thalamus it is expressed throughout the mantle, although it is expressed at higher levels in a deep and in a superficial mantle zone (Figs. $3 c ; 4 a, b$ ). These two zones may correspond to domains within the dorsal thalamus where distinct nuclei are developing. For instance, the more superficial zone may be where nuclei such as the lateral and medial geniculate nuclei will be forming.

The diencephalic expression of the $W n t-3$ and $G b x-2$ genes partially overlaps within $\mathrm{p} 2$. They are both expressed in the dorsal thalamus, and have the same caudal and rostral boundaries (at $\mathrm{p} 1$ and at $\mathrm{p} 3$, respectively; note, however, that the $\mathrm{p} 1 /$ p2 boundary is not absolutc for $W n t-3$ because it is expressed in a dorsally restricted zone in $\mathrm{pl}$ ). The rostral boundary abuts the expression of the $D l x$ genes in $\mathrm{p} 3$. We conceive of these transverse boundaries as neuromeric limits and will discuss this point later in this article.

$G b x-2$ and $W n t-3$ expression in $\mathrm{p} 2$ differ in three ways. First, they have different dorsal and ventral boundaries (see Results and the last section of Discussion). Second, within the dorsal thalamus the expression of $G b x-2$ is largely limited to the mantle, whereas $W n t-3$ is expressed in both the ventricular zone and in the mantle. Therefore, $W n t-3$ is expressed in the undifferentiated mitotically active neuroepithelial cells as well as in the differentiating cells of the mantle. This potentially signifies that $W n t-3$ is above $G b x-2$ in the genetic hierarchy that controls differentiation of the dorsal thalamus.

The last difference is that $G b x-2$ and $W n t-3$ are expressed in complementary patterns within the dorsal thalamus (Figs. $1 i-$ $p, 4 a-d)$. One possible explanation of these reciprocal gradients is that $G b x-2$ and $W n t-3$ either directly or indirectly inhibit each other's expression. Interactions between homeobox and wingless-type genes have been clearly demonstrated in Drosophila for the en, Dll, and wg genes (Cohen, 1990; Heemskerk et al., 1991), and have been hypothesized between the $E n-I$ and $W n t-I$ genes in mouse (McMahon et al., 1992). It is also possible that $W n t-3$ inhibits the expression of the $D l x$ genes at the zona limitans.

\section{Expression patterns in the embryonic forebrain of other putative regulatory molecules}

Our work with $D l x-1, D l x-2, G b x-2$, and $W n t-3$ shows that the expression patterns of putative regulatory molecules can delineate specific domains within the embryonic forebrain. Recently, a number of other genes have been isolated that are also expressed in spatially restricted domains in the embryonic forebrain, some of which we have included in our model of forebrain segmentation. Several of these encode transcription or growth factors. Price et al. (1992) reported on the expression of a new family of homeobox-containing genes named $N k x-2$, and they compared the expression of $N k x-2.1, N k x-2.2$, and $D l x-1$. All three of these genes are expressed in discontinuous domains in the forebrain. Their results with $D l x-1$ are in complete accord with our findings. Other homeobox-containing genes are also expressed in restricted domains of the forebrain. These include $E m x-1$ and $E m x-2$ (Simeone et al., 1992a), Otx-1 and Otx-2 (Simeone et al., 1992b), $D b x$ (Lu et al., 1992), Hox-7 (MacKenzie et al., 1991), Pax-3 (Goulding et al., 1991), Pax-6 (Walther and Gruss, 1991), Pax-7 (Jostes et al., 1991), Oct-6 (Suzuki et al., 1990), and Brain 4 (Mathis et al., 1992). Three helixloop-helix genes have restricted patterns of forebrain expression. 
These include the MASHI (Lo et al., 1991), Heir- 1 and $N$-myc genes (Ellmeier et al., 1992). Finally, Tao and Lai (1992) found that neural expression of the $B F-1$ gene, which is a member of the $H N F-3 /$ fork-head transcription factor family, is restricted to the telencephalon.

Several putative secreted differentiation factors and their receptors are also expressed in discrete locations in the forebrain neuroepithelium. Included among these are $W n t-3 a$ (Roelink and Nusse, 1991), $W n t-7 b$ and $W n t-5 a$ (McMahon et al., 1992), $B M P-4$ (Jones et al., 1991), and FGF receptor genes 1 and 2 (Peters et al., 1992).

Given the complexity of the mammalian forebrain, this list of potential regulatory molecules will undoubtedly be just the beginning. Despite this early stage in understanding the molecular control of forebrain development, one can begin to make hypotheses about the molecular mechanisms that might control regional specification, by drawing from the work that has been done in Drosophila. It is becoming increasingly clear that many of the genes that regulate development in Drosophila have analogous functions in vertebrates. Furthermore, the embryologic and molecular strategies for the generation of the body plan used in Drosophila may also have relevance in vertebrates. Thus, it is possible that fate maps of the adult mammalian brain are encoded within the ventricular zone of the embryonic brain by specific combinations of transcriptional regulators, and that transverse and longitudinal zones are used to restrict the spatial expansion of cell lineages. Development of the vertebrate rhombencephalon appears to follow this model (Fraser et al., 1990; Hunt et al., 1991; Guthrie et al., 1992). In the next section, we will present evidence that the mouse forebrain may also develop using a similar strategy.

\section{Transverse and longitudinal domains in the forebrain}

It is now well established that the hindbrain is composed of transverse segments known as rhombomeres (Vaage, 1969; Lumsden and Keynes, 1989; Guthrie et al., 1991). These are discernible by virtue of their morphological characteristics, that is, transverse ridges and furrows, as well as specific patterns of gene expression (Hunt et al., 1991), and boundaries that restrict cell migrations between the rhombomeres (Fraser et al., 1990). Perpendicular to the rhombomeres there are at least two longitudinal domains in the hindbrain that are in essence a continuation of the longitudinal zones of spinal cord: the dorsal (alar) plate and the ventral (basal) plate. The data described in this article are consistent with the view that the forebrain has longitudinal and transverse (neuromeric) domains analogous to those in the rhombencephalon.

The forebrain (prosencephalon), which is the rostralmost region of the neural tube, is subdivided into two proneuromeric transverse domains: the diencephalon and the secondary prosencephalon (Puelles et al., 1987). The secondary prosencephalon consists of the telencephalic and optic vesicles, the preoptic area, and the hypothalamus (Figs. 6, 7). In the E12.5 mouse, the rostralmost region of the neural tube becomes the basal forebrain due to the curvature of the longitudinal axis at the cephalic flexure. Thus, to obtain a correct representation of the longitudinal and transverse relationships within the brain, the forebrain needs to be rotated counterclockwise $90^{\circ}$ (see Fig. 7). Once this is done, one can appreciate that the base of the secondary prosencephalon (see the position of SCH, POP, POA, DB, SE, and $\mathrm{OB}$ in Fig. 6) is actually the rostralmost region of the brain, and much of the hypothalamus (MA, TU, and $\mathrm{RCH}$ ) is a longitudinal extension of the basal plate (Fig. 7).

Several schools of neuroembryology have constructed different schemas for conceptualizing the fundamental structural organization of the embryonic vertebrate forebrain. The approach introduced by Herrick emphasized longitudinal columns limited by sulci that subdivide the forebrain (Herrick, 1910, 1933, 1948; Kuhlenbeck, 1973). Recently, several workers have interpreted the expression data of the $D l x-1$ (Price et al., 1991) and the $E m x$ genes (Simeone et al., 1992a) in terms of this model. However, problems arise from the use of the longitudinal columns model for several reasons. First and foremost, it fails to define the primary longitudinal axis of the brain by not taking into account the bending of the neural tube axis at the cephalic flexure (see above). Next, it relies on morphological markers, in particular sulci in the ventricular zone, as the boundaries between different domains. As shown by Price et al. (1991) and the present results, the $\mathrm{p} 2 / \mathrm{p} 3$ boundary of $D l x-1$ and $D l x-2$ expression coincides with a ventricular ridge and not with the nearby sulcus. Finally, the columnar model lacks an integrated conception of forebrain subdivisions, and considers the telencephalon and diencephalon as separate "vesicles."

Another approach, the neuromeric theory, postulates the existence of both transverse and longitudinal domains that subdivide the embryonic brain into regions that follow distinct developmental pathways (von Kupffer, 1906; Rendahl, 1924; von Haller, 1929; Bergquist, 1932; Bergquist and Kallen, 1954, 1955; Coggeshall, 1964; Kallen, 1965; Vaage, 1969; Keyser, 1972; Gribnau and Geijsberts, 1983; Altman and Bayer, 1986, 1988; Puelles et al., 1987, 1991, 1992; Lakke et al., 1988). This theory takes into account the bending of the longitudinal axis at the cephalic flexure. The initial evidence for this model came from the observation of ventricular ridges and external furrows in the outer wall of the neural tube (see Puelles et al., 1987, 1991, for a review). More recent studies have used the patterns of cell proliferation (Altman and Bayer, 1986, 1988), the position of fiber tracts, and molecular markers of differentiation to distinguish different domains. These markers include AChE (Puelles et al., 1987; Layer et al., 1988; Hanneman and Westerfield, 1989; Wilson et al., 1990), GABA (Roberts et al., 1987), and several axonal components (Edwards et al., 1989; Wilson et al., 1990; Easter et al., 1992, 1993).

This work supports the existence of longitudinal zones (alar and basal) that span the brain and whose rostralmost limit is just behind the optic stalks. The longitudinal zoncs appcar to be divided into transverse domains in both the diencephalon and the secondary prosencephalon (which includes the telencephalon); this is suggested by the pattern of $\mathrm{AChE}$ expression and by morphological structures that are characteristic of neuromeres (Puelles et al., 1987; Easter et al., 1992; Fernandez, Caballero-Bada, and Puelles, unpublished observations). Furthermore, as described below, the expression patterns of genes encoding putative regulatory molecules are consistent with this model of the organization of the embryonic brain.

To simplify the nomenclature, we are naming the transverse zones of the forebrain as prosomeres in accordance with the work of Fernandez, Caballero-Blada and Puelles (unpublished observations) (see Figs. 6, 7). There are three diencephalic and three secondary prosencephalic prosomeres: $\mathrm{pl}$ is the most caudal and $\mathrm{p} 6$ is the most rostral; $\mathrm{pl}$ corresponds to the synencephalon (whose alar component is the pretectum), $\mathrm{p} 2$ corresponds to the posterior parencephalon (whose alar components are the 
dorsal thalamus and the epithalamus), and $\mathrm{p} 3$ corresponds to the anterior parencephalon (whose alar component is the ventral thalamus).

\section{Transverse and longitudinal domains of gene expression in the diencephalon}

The spatially restricted patterns of expression of the $D l x-1 / 2$, $G b x-2$, and $W n t-3$ genes fit within the framework of the proposed longitudinal and transverse regions of the diencephalon (Figs. 6, 7). For example, the $\mathrm{p} 2$ segment is delineated by the expression of $W n t-3$ and $G b x-2$, whereas the $D l x$ genes are expressed in $\mathrm{p} 3-\mathrm{p} 6$. Thus, the $\mathrm{p} 1 / \mathrm{p} 2$ boundary is defined by the caudal limit of the expression of $G b x-2$ and of $W n t-3$ (within the mantle). The $\mathrm{p} 2 / \mathrm{p} 3$ boundary (known as the zona limitans, and precursor of the external medullary lamina of the thalamus) is defined by the rostral limit of the expression of $G b x-2$ and $W n t-3$, and by the caudal limit of the expression of the $D l x$ genes. The expression of other genes also respects these transverse boundaries. For instance, calbindin is expressed within the dorsal thalamus (alar p2) in the embryonic rat (Puelles et al., 1992). Furthermore, the zona limitans expresses the $W n t-$ $3 a$ gene (Roelink and Nusse, 1991). These transverse zones also have the morphological characteristics of neuromeres; ventricular ridges and external furrows arc present at the boundaries between p1 (PT), p2 (DT), and p3 (VT) (Fig. 5J).

I ongitudinal zones within the diencephalon can also be appreciated by observing the patterns of expression of $D l x-1 / 2$, $G b x-2$, and $W n t-3$. Expression of these genes is restricted to the alar plate. Furthermore, in $\mathrm{p} 2$ the expression patterns of $G b x-2$ and $W n t-3$ define four different longitudinal zones: epithalamus ( $W n t-3$ positive), dorsal thalamus ( $W n t-3$ and $G b x-2$ positive), an unnamed boundary zone ( $W n t-3$ positive), and the basal plate, which expresses neither gene. The basal plate appears to express the $W n t-1$ and $W n t-5 a$ gene (McMahon et al., 1992) and the DM-20 transcript of the myelin PLP gene (Timsit et al., 1992).

\section{Transverse and longitudinal domains of gene expression in the} secondary prosencephalon

Morphological analyses of the subdivisions within the secondary prosencephalon (telencephalon and hypothalamus) have been previously conducted by several workers including Bergquist and Kallen (1954), Smart (1985), and Bayer and Altman (1991). The organization of the secondary prosencephalon into transverse domains is uncertain because of the lack of clear morphological markers of segmentation. Bergquist and Kallen proposed a model that divided the secondary prosencephalon into two transverse segments (see a review by Bergquist, 1964), and recent morphological analysis of the rat embryonic forebrain supports this concept (Fernandez, Caballero-Blada, and Puelles, unpublished observations). Furthermore, the existence of a third transverse domain in the secondary prosencephalon, which includes the eye vesicles and the attached optic stalk region, is consistent with the results in this article and the results of others. Thus, we postulate the existence of three prosomeres (p4, p5, and p6) in the secondary prosencephalon (Figs. 6, 7). The reasoning that supports this model is briefly summarized below.

The existence of transverse domains within the secondary prosencephalon can be postulated on the basis of the expression patterns of various genes, including $D l x-1, D l x-2$, and $G b x-2$ (see Results); $E m x-1$ and $E m x-2$ (Simeone et al., 1992a,b); Otx-1 and Otx-2 (Simeone et al., 1992b); Hox-7 (MacKenzie et al., 1991); $P a x-2$ (Nornes et al., 1990), Pax-3 (Goulding et al., 1991); Pax-6 (Walther and Gruss, 1991), Pax-7 (Jostes et al., 1991), Pax[zf-a] and Pax[zf-b] (Krauss et al., 1991); Wnt-I (Wilkinson et al., 1987; McMahon et al., 1992); Wnt-3a (Roelink and Nusse, 1991), Wnt-5a and $W n t-7 b$ (McMahon et al., 1992); $N k x-2.1$ and $N k x-2.2$ (Price et al., 1992); BF- $I$ (Tao and Lai, 1992); heir-l and $N$-myc (Ellmeier et al., 1992); Mashl (Lo et al., 1991). We have analyzed the expression patterns of these genes from the published data. Our interpretation of the expression of most of these genes along the longitudinal axis is shown in Figure 7. Each gene is expressed in spatially restricted domains that end at boundaries that we interpret to be the limits of the prosomeres. For instance, expression of $N-m y c, W n t-5 a$, and $E m x-2$ ends at the $\mathrm{p} 3 / \mathrm{p} 4$ boundary; expression of $D l x-1 /$ 2 , heir-1, N-myc, Otx-1, and $W n t-3 a$ ends at the p4/p5 boundary; expression of $G b x-2, P a x[z f-b], P a x-2, P a x-7$, and Otx-2 ends at the $\mathrm{p} 5 / \mathrm{p} 6$ boundary. There are two caveats in this analysis. First, it is difficult to determine accurately the position of the expression boundaries of some of these genes in the absence of internal markers. Second, the expression patterns for many of these genes have not been determined for the E12.5 mouse brain. Thus, future studies will be needed to compare directly the expression patterns of these genes at several stages of brain development.

The model in Figure 7 also shows mutliple longitudinal zones. These strata are based on morphological considerations and on the patterns of gene expression. The most ventral level is a continuation of the basal plate, which contains the hypothalamic areas (His, 1893; Puelles et al., 1987). Dorsal to this is a $D l x$ positive alar zone, which is separated from more dorsal regions by a $D l x$-negative longitudinal zone consisting of the SPV (p4), $\mathrm{AH}$ (p5), and the POP (p6). The next postulated zone runs along the stalk of the cerebral hemisphere and includes the EMT (p4), AEP (p5), and POA (p6) areas. Inside the telencephalic vesicles, there are three hypothetical longitudinal zones. The one closest to the hemispheric stalk includes the medial part of the CGE (p4), MGE (p5), and DB (p6). The next stratum consists possibly of the lateral part of the CGE (p4), the LGE (p5), and the SE (p6). Above this layer are the allocortex/endopiriform nucleus (ACX, p4), the neocortex and the claustrum (NCX, p5) and the olfactory bulb and olfactory nucleus $(\mathrm{OB}, \mathrm{p} 6)$. The most superficial layer contains the chorioid plexus $(\mathrm{CH})$ and commissural plate (not shown).

Thus, the transverse and longitudinal divisions that are postulated in the topological map in Figure 7, are a model based upon our observations of the expression patterns of pulative regulatory genes and the morphology of the embryonic forebrain. Definitive anatomical correlations between these genes will require in situ RNA hybridization analysis on neighboring sections with each of these genes. As the transcription patterns of other potential regulatory genes are examined, this model for forebrain segmentation will be refined and appended. For the time being, we intend to use this model as a reference point from which to design experiments to test whether the forebrain is indeed segmented. As in the case of the rhombomeres, additional support of the neuromeric organization of the forebrain will come from data showing that there are lineage restrictions (Fraser et al., 1990) as well as proliferative heterogeneities in the ventricular zone (Guthrie et al., 1991) across the postulated transverse segmental boundaries. 


\section{References}

Acampora D, D'Esposito M, Faiella A, Pannese M, Migliaccio E, Morelli F, Stornaiuolo A, Nigro V, Simeone A, Boncinelli E (1989) The human HOX gene family. Nucleic Acids Res 17:10385-10402.

Altman J, Bayer SA (1986) The development of the rat hypothalamus. Adv Anat Embryol Cell Biol 100:1-177.

Altman J, Bayer SA (1988) Development of the rat thalamus: I. Mosaic organization of the thalamic neuroepithelium. J Comp Neurol 275: 346-377.

Baker NE (1987) Molecular cloning of sequences from wingless, a segment polarity gene in Drosophila: the spatial distribution of a transcript in embryos. EMBO J 6:1765-1773.

Bayer SA, Altman J (1991) Neocortical development. New York: Raven.

Bergquist H (1932) Zur Morphologie des Zwischenhirns bei niederen Wierbeltieren. Acta Zool 13:57-303.

Bergquist $H$ (1964) The formation of the frontal part of the neural tube. Experientia 20:92-93.

Bergquist H, Kallen B (1954) Notes on the early histogenesis and morphogenesis of the central nervous system in vertebrates. J Comp Neurol 100:627-660.

Bergquist H, Kallen B (1955) The archencephalic neuromery in Ambystoma punctatum. An experimental study. Acta Anat 24:208-214.

Bulfone A, Kim H-J, Puelles L, Porteus MH, Grippo JF, Rubenstein JLR (1993) The mouse $D l x-2($ Tes-1) gene is expressed in spatially restricted domains of the forebrain, face and limbs in midgestation mouse embryos. Mech Dev, in press.

Chisaka O, Capecchi MR (1991) Regionally restricted developmental defects resulting from targeted disruption of the mouse homeobox gene Hox-1.5. Nature 350:473-479.

Chisaka O, Musci TS, Capecchi MR (1992) Developmental defects of the ear, cranial nerves and hindbrain resulting from targeted disruption of the mouse homeobox gene Hox-1.6. Nature 355:516-520.

Coggeshall RE (1964) A study of diencephalic development in the albino rat. J Comp Neurol 122:241-270.

Cohen SM (1990) Specification of limb development in the Drosophila embryo by positional cues from segmentation genes. Nature 343:173177.

Cohen SM, Brönner G, Küttner F, Jürgens G, Jäckle H (1989) Distalless encodes a homeodomain protein required for limb development in Drosophila. Nature 338:432-434.

DiNardo S, Sher E, Heemskerk-Jongens J, Kassis JA, O'Farrell PH (1988) Two-tiered regulation of spatially patterned engrailed gene expression during Drosophila embryogenesis. Nature 332:604-609.

Dollé P, Price M, Duboule D (1992) Expression of the murine $D l x-1$ homeobox gene during facial, ocular and limb development. Differentiation 49:93-99.

Duboule D, Dolle P (1989) The structural and functional organization of the murine Hox gene family resembles that of Drosophila homeotic genes. EMBO J 8:1497-1505.

Easter SS Jr, Wilson SW, Ross LS, Burrill JD (1992) Tract formation in the brain of the zebrafish embryo. In: The nerve growth cone (Letourneau PC, Kater SB, Macagno ER, eds), pp 337-351. New York: Raven.

Easter SS Jr, Ross LS, Frankfurter A (1993) Initial tract formation in the mouse brain. J Neurosci 13:285-299.

Fdwards MA, Crandall JE, Wood JN, Tanaka H, Yamamoto M (1989) Early axonal differentiation in mouse CNS delineated by an antibody recognizing extracted neurofilaments. Dev Brain Res 49:185-204.

Ellmeier W, Aguzzi A, Kleiner E, Kurzbauer R, Weith A (1992) Mutually exclusive expression of a helix-loop-helix gene and $\mathrm{N}-m y c$ in human neuroblastomas and in normal development. EMBO J 11 : 2563-2571.

Fainsod A, Greunbaum Y (1989) A chicken homeobox gene with developmentally regulated expression. FEBS Lett 250:381-385.

Fraser S, Keynes R, Lumsden A (1990) Segmentation in chick embryo hindbrain is defined by cell lineage restrictions. Nature 344:431-435.

Frohman MA, Dickinson ME, Hogan BLM, Martin GR (in press) Mapping of $G b x-1$ to mouse chromosome 5 and $G b x-2$ to mouse chromosome 1. Mouse Genome, in press.

Gehring WJ (1987) Homeo boxes in the study of development. Science 236:1245-1252.

Goulding MD, Chalepakis G, Deutsch U, Erselius JR, Gruss P (1991) Pax-3, a novel murine DNA binding protein expressed during carly neurogenesis. EMBO J 10:1135-1147.
Graham A, Papalopulu N, Krumlauf R (1989) The murine and Drosophila homeobox gene complexes have common features of organization and expression. Cell 57:367-378.

Gribnau AAM, Geijsberts LGM (1985) Morphogenesis of the brain in staged rhesus monkey embryos. Adv Anat Embryol Cell Biol 91: $1-69$.

Guthrie S, Butcher M, Lumsden A (1991) Patterns of cell division and interkinetic nuclear migration in the chick embryo hindbrain. $\mathrm{J}$ Neurobiol 22:742-754.

Guthrie S, Muchamore I, Kuroiwa A, Marshall H, Krumlauf R, Lumsden A (1992) Neuroectodermal autonomy of Hox-2.9 expression revealed by rhombomere transpositons. Nature 356:157-159.

Hanneman E, Westerfield M (1989) Early expression of acetylcholinesterase activity in functionally distinct neurons of the zebrafish. $J$ Comp Neurol 284:350-361.

Heemskerk J, DiNardo S, Kostriken R, O'Farrell PH (1991) Multiple modes of engrailed regulation in the progression towards cell fate determination. Nature 352:404-410.

Herrick CJ (1910) The morphology of the forebrain in amphibia and reptilia. J Comp Neurol 20:413-547.

Herrick CJ (1933) Morphogenesis of the brain. I Morphol 54:233258.

Herrick CJ (1948) The brain of the tiger salamander. Chicago: Chicago UP.

His W (1893) Uber die frontale ende des gehirurohes. Arch Anat Entwicklungsgesch (Lepizig) 157-171.

I Iunt P, Gulisano M, Cook M, Sham M-H, Faiella A, Wilkinson D, Boncinelli E, Krumlauf R (1991) A distinct Hox code for the branchial region of the vertebrate head. Nature 353:861-864.

Jones CM, Lyons KM, Hogan BLM (1991) Involvement of bone mor phogenetic protein-4 (BMP-4) and Vgr- 1 in morphogenesis and neurogenesis in the mouse. Development 111:531-542.

Jostes B, Walther C, Gruss P (1991) The murine paired box gene, PaX-7, is expressed specifically during the development of the nervous and muscular system. Mech Dev 33:27-38.

Kallen B (1965) Early morphogenesis and pattern formation in the central nervous system. In: Organogenesis (De Haan RL, Ursprung H, eds), pp 107-128. New York: Holt, Rhinehart \& Wilson.

Kappen C, Schughart K, Ruddle FH (1989) Two steps in the evolution of Antennapedia-class vertebrate homeobox genes. Proc Natl Acad Sci USA 86:5459-5463.

Keyser A (1972) The development of the diencephalon of the chinese hamster. Acta Anat 83[Suppl 59]:1-181.

Krauss S, Johansen T, Korzh V, Fjose A (1991) Expression pattern of zebrafish pax genes suggests a role in early brain regionalization. Nature 353:267-270.

Kuhlenbeck H (1973) The central nervous system of vertebrates, Vol 3, Pt II, Overall morphologic pattern. Basel: Karger.

I akke F.AJF, van der Veeken JGPM, Mentink MMT, Marani F. (1988) A SEM study on the development of the ventricular surface morphology in the diencephalon of the rat. Anat Embryol (Berl) 179:7380.

Layer PG, Rommel S, Bülthoff H, Hengstenberg R (1988) Independent spatial spatial waves of biochemical differentiation along the surface of chicken brain as revealed by the sequential expression of acetylcholinesterase. Cell Tissue Res 251:587-595.

Levine MS, Harding KW (1989) Drosophila: the zygotic contribution. In: Genes and embryos (Glover DM, Hames BD, eds), pp 39-94. Oxford: IRL.

Lo L-C, Johnson JE, Wuenschell CW, Saito T, Anderson DJ (1991) Mammalian achaete-scute homolog 1 is transiently expressed by spatially restricted subsets of early neuroepithelial and neural crest cells. Genes Dev 5:1524-1537.

Lu S, Bogarad LD, Murtha MT, Ruddle FH (1992) Expression pattern of a murine homeobox gene, $D b x$, displays extreme spatial restriction in embryonic forebrain and spinal cord. Proc Natl Acad Sci USA 89: 8053-8057.

Lufkin T, Dierich A, LeMeur M, Mark M, Chambon P (1991) Disruption of the Hox-1.6 homeobox gene results in defects in a region corresponding to its rostral domain of expression. Cell 66:1 105-1119.

Lumsden A, Keynes R (1989) Segmental patterns of neuronal development in the chick hindbrain. Nature 33:424-428.

MacKenzie A, Ferguson MWJ, Sharpe PT (1991) Hox-7 expression during murine craniofacial development. Development 113:601-611. Mathis JM, Simmons DM, He X, Swanson LW, Rosenfeld MG (1992) 
Brain 4: a novel mammalian POU domain transcription factor exhibiting restricted brain-specific expression. EMBO J 11:2551-2561.

McGinnis W, Krumlauf R (1992) Homeobox genes and axial patterning. Cell 68:283-302.

McGuinnis TL, MacDonald GP, Koch TK, Rubenstein JLR (1992) Evidence for linkage of Tes- 1 and $D l x-1$, two homeobox genes expressed in the developing mammalian forebrain. Soc Neurosci Abstr 18.

McMahon AP, Joyner AL, Bradley A, McMahon JA (1992) The midbrain-hindbrain phenotype of $W n t-1^{-} / W n t-1^{-}$mice results from stepwise deletion of engrailed-expressing cells by 9.5 days postcoitum. Cell 69:581-595.

Murtha MT, I eckman JF, Ruddle FH (1991) Detection of homeobox genes in development and evolution. Proc Natl Acad Sci USA 88: 10711-10715.

Norncs HO, Dressler GR, Knapik EW, Deutsch U, Gruss P (1990) Spatially and temporally restricted expression of $\mathrm{Pax}-2$ during murine neurogenesis. Development 109:797-809.

Nusse R, Varmus HE (1992) Wnt genes. Cell 69:1073-1087.

Özcelik T, Porteus MH, Rubenstein JLR, Francke U (1992) $D l x-2$ (Tes1), a homeobox gene of the distal-less family, assigned to conserved regions on human and mouse chromosomes 2. Genomics 13: $1157-1161$.

Peters KG, Werner S, Chen G, Williams LT (1992) Two FGF receptor genes are differentially expressed in epithelial and mesenchymal tissues during limb formation and organogenesis in the mouse. Development 114:233-243.

Porteus MH, Bulfone A, Ciaranello RD, Rubenstein JLR (1991) Isolation and characterization of a novel cDNA clone encoding a homeodomain that is developmentally regulated in the ventral forebrain. Neuron 7:221-229.

Porteus MH, Brice AEJ, Bulfone A, Usdin TB, Ciaranello RD, Rubenstein JLR (1992) Isolation and characterization of a library of cDNA clones that are preferentially expressed in the embryonic telencephalon. Mol Brain Res 12:7-22.

Price M, Lemaistre M, Pischetola M, Di Lauro R, Duboule D (1991) A mouse gene related to distal-less shows a restricted expression in the developing forebrain. Nature 351:748-751.

Price M, Lazzaro D, Pohl T, Mattei M-G, Rüther U, Olivo J-C, Duboule D, Di Lauro R (1992) Regional expression of the homeobox gene $N k x-2.2$ in the developing mammalian forebrain. Neuron 8:241-255.

Puelles L, Amat JA, Martinez-de-la-Torre M (1987) Segment-related, mosaic neurogenetic pattern in the forebrain and mesencephalon of early chick embryos: I. Topography of AChE-positive neuroblasts up to stage HH18. J Comp Neurol 266:247-268.

Puelles L, Guillen M, Martinez-de-la-Torre M (1991) Observations on the fate of the nucleus superficialis magnocellularis of Rendahl in the avian diencephalon, bearing on the organization and nomenclature of neighboring retinorecipient nuclei. Anat Embryol (Berl) 183: 221-233.

Puelles L, Sánchez MP, Spreafico R, Fairén A (1992) Prenatal development of calbindin immunoreactivity in the dorsal thalamus of the rat. Neuroscience 46:135-147.

Rendahl H (1924) Embryologische und morphologische Studien über das Zwischenhirn beim Huhn. Acta Zool 5:241-344.
Rijsewijk F, Schuermann M, Wagenaar E, Parren P, Weigel D, Nusse $\mathrm{R}$ (1987) The Drosophila homolog of the mouse mammary oncogene int -1 is identical to the segment polarity gene wingless. Cell $50: 649$ 657.

Roberts A, Dale N, Ottersen OP, Storm-Mathisen J (1987) The early development of neurons with GABA immunoreactivity in the CNS of Xenopus laevis embryos. J Comp Neurol 261:435-449.

Robinson GW, Wray S, Mahon KA (1991) Spatially restricted expression of a member of a new family of murine distal-less homeobox genes in the developing forebrain. New Biol 3:1183-1194.

Roelink H, Nusse R (1991) Expression of two members of the Wnt family during mouse development-restricted temporal and spatial patterns in the developing neural tube. Genes Dev 5:381-388.

Rubenstein JLR, Brice AEJ, Ciaranello RD, Denney D, Porteus MH, Usdin TB (1990) Subtractive hybridization system using singlestranded phagemids with directional inserts. Nucleic Acids Res 18 $4833-4842$.

Simeone A, Gulisano M, Acampora D, Stornaiuolo A,. Rambaldi M, Boncinelli E (1992a) Two vertebrate homeobox genes related to the Drosophila empty spiracles gene are expressed in the embryonic cerebral cortex. EMBO J 11:2541-2550.

Simeone A, Acampora D, Gulisano M, Stornaiuolo A, Boncinelli E (1992b) Nested expression domains of four homeobox genes in developing rostral brain. Nature 358:687-690.

Smart IHM (1985) Differential growth of the cell production systems in the lateral wall of the developing mouse telencephalon. J Anat 141: 219-229.

Suzuki N, Rohdewohld H, Neuman T, Gruss P, Scholer HR (1990) Oct-6: a POU transcription factor expressed in embryonal stem cells and in the developing brain. EMBO J 9:3723-3732.

Tao W, Lai E (1992) Telencephalon-restricted expression of BF-1, a new member of the HNF-3/fork head gene family, in the developing rat brain. Neuron 8:957-966.

Timsit SG, Bally-Cuif L, Colman DR, Zalc B (1992) DM-20 mRNA is expressed during the embryonic development of the nervous system of the mouse. J Neurochem 58:1172-1175.

Vaage $S$ (1969) The segmentation of the primitive neural tube in chick embryos (Gallus domesticus). Adv Anat Embryol Cell Biol 41:1-87.

von Haller G (1929) Die Gliederung des Zwischen- und Mittelhirns der Wirbeltiere. Morphol Jahrb 63:359-409.

von Kupffer K (1906) Die Morphogenie des Zentralnervensystems. In: Handbuch der vergleichenden und experimentellen Entwicklungslehre der Wirbeltiere, Vol II, Teil 3 (Hertwig O, ed). Jena: Gustav Fisher.

Walther C, Gruss P (1991) Pax-6, a murine paired box gene, is expressed in the developing CNS. Development 113:1435-1449.

Wilkinson DG, Bailes JA, McMahon AP (1987) Expression of the proto-oncogene int- 1 is restricted to specific neural cells in the developing mouse embryo. Cell 50:79-88.

Wilson SW, Ross LS, Parrett T, Easter SS Jr (1990) The development of a simple scaffold of axon tracts in the brain of the embryonic zebrafish, Brachydanio rerio. Development 108:121-145.

Zoeller RT, Lebacq-Verheyden A-M, Battey JF (1989) Distribution of two distinct messenger ribonucleic acids encoding gastrin-releasing peptide in rat brain. Peptides 10:415-422. 